\title{
Advances in managing the noninfected open chest after cardiac surgery: Negative-pressure wound therapy
}

Faisal G. Bakaeen, MD, ${ }^{\mathrm{a}}$ Osama Haddad, MD, ${ }^{\mathrm{a}}$ Mudathir Ibrahim, MD, ${ }^{\mathrm{a}}$ Selena R. Pasadyn, BA, Emídio Germano, MD, ${ }^{a}$ Salvior Mok, MD, ${ }^{a}$ M. Scott Halbreiner, MD, ${ }^{a}$ Kenneth R. McCurry, MD, Douglas R. Johnston, MD, ${ }^{a}$ Stephanie L. Mick, MD, ${ }^{a}$ José L. Navia, MD, ${ }^{a}$ Eric E. Roselli, MD, ${ }^{a}$ Nicholas G. Smedira, MD, ${ }^{a}$ Edward G. Soltesz, MD, ${ }^{a}$ Michael Z. Tong, MD, MBA, ${ }^{a}$ Per Wierup, MD, PhD, ${ }^{a}$ A. Marc Gillinov, MD, ${ }^{\mathrm{a}}$ Lars G. Svensson, MD, PhD, ${ }^{\mathrm{a}}$ Penny L. Houghtaling, MS, ${ }^{\mathrm{b}}$ Eugene H. Blackstone, MD, ${ }^{\mathrm{a}, \mathrm{b}}$ and Gösta B. Pettersson, $\mathrm{MD}, \mathrm{PhD}^{\mathrm{a}}$

\section{ABSTRACT}

Objective: The objective of this study was to compare safety and clinical effectiveness of negative-pressure wound therapy (NPWT) with traditional wound therapy for managing noninfected open chests with delayed sternal closure after cardiac surgery.

Methods: From January 2000 to July 2015, 452 of 47,325 patients who underwent full sternotomy left the operating room with a noninfected open chest $(0.96 \%)$, managed using NPWT in 214-with frequency of use rapidly increasing to near $100 \%$ - and traditionally in 238. Predominant indications for open-chest management were uncontrolled coagulopathy or hemodynamic compromise on attempted chest closure. Weighted propensity-score matching was used to assess in-hospital complications and time-related survival.

Results: NPWT and traditionally managed patients had similar high-risk preoperative profiles. Most underwent reoperations $(63 \%$ of the NPWT group and $57 \%$ of the traditional group), and $21 \%$ versus $25 \%$ were emergency procedures. Reexplorations for bleeding were less common with NPWT versus traditional wound therapy $(\mathrm{n}=63[29 \%$ ] vs $104[44 \%], P=.002)$. Median duration of open-chest to definitive sternal closure was 3.5 days for NPWT versus 3.1 for traditionally managed patients $(P[\log$ rank $]=.07)$. Seven patients $(3.3 \%)$ were converted from NPWT to traditional therapy because of hemodynamic intolerance and $6(2.5 \%)$ from traditional to NPWT. No NPWT-related cardiovascular injuries occurred. Among matched patients, NPWT was associated with better early survival ( $61 \%$ vs $44 \%$ at 6 months; $P=.02)$.

Conclusions: NPWT is safe and effective for managing noninfected open chests after cardiac surgery. By facilitating open-chest management and potentially improving outcomes, it has become our therapy of choice and perhaps has lowered our threshold for leaving the chest open after cardiac surgery. (J Thorac Cardiovasc Surg 2019;157:1891-903)

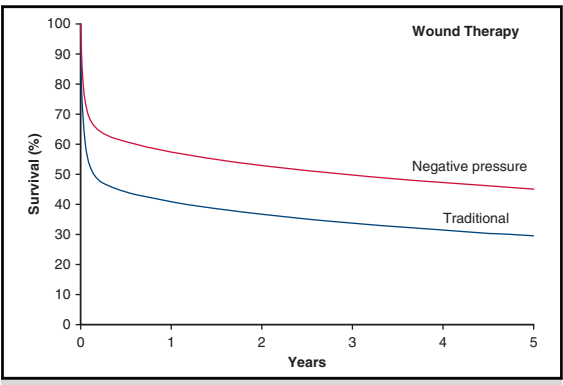

Survival after negative-pressure and traditional wound therapy for open-chest management.

\section{Central Message}

Negative-pressure wound therapy for noninfected open-chest management is safe, associated with fewer re-explorations for bleeding, and better survival compared with traditional wound management.

Perspective

Bleeding, coagulopathy, and hemodynamic compromise force cardiac surgeons to leave the chest open. By facilitating management and reducing re-explorations for bleeding, negative-pressure wound therapy quickly emerged as our strategy of choice. It is associated with better survival than traditional management and may have lowered our threshold for leaving the chest open after cardiac surgery.

See Commentary on page 1904.

\footnotetext{
From the ${ }^{\mathrm{a}}$ Heart and Vascular Institute, Department of Thoracic and Cardiovascular Surgery, and ${ }^{b}$ Research Institute, Department of Quantitative Health Sciences, Cleveland Clinic, Cleveland, Ohio.

This study was funded in part by the Gus P. Karos Registry Fund, the David Whitmire Hearst, Jr. Foundation, the Marty and Michelle Weinberg and Family Fund, the Sheikh Hamdan bin Rashid Al Maktoum Distinguished Chair in Thoracic and Cardiovascular Surgery, the Stephens Family Endowed Chair in Cardiothoracic Surgery, the Delos M. Cosgrove, MD, Chair for Heart Disease Research, the Drs Sidney and Becca Fleischer Heart and Vascular Education Chair, the Peter and Elizabeth C. Tower and Family Endowed Chair in Cardiothoracic Research, James and Sharon Kennedy, the Slosburg Family Charitable Trust, Stephen and Saundra Spencer, and Martin Nielsen.
}

Read at the 98th Annual Meeting of The American Association for Thoracic Surgery, San Diego, California, April 28-May 1, 2018.

Received for publication April 23, 2018; revisions received Aug 31, 2018; accepted for publication Oct 9, 2018; available ahead of print Jan 29, 2019.

Address for reprints: Gösta B. Pettersson, MD, PhD, Department of Thoracic and Cardiovascular Surgery, Cleveland Clinic, 9500 Euclid Ave/Desk J4-1, Cleveland, OH 44915 (E-mail: petterg@ ccf.org).

$0022-5223 / \$ 36.00$

Copyright $@ 2018$ Published by Elsevier Inc. on behalf of The American Association for Thoracic Surgery

https://doi.org/10.1016/j.jtcvs.2018.10.152 


\section{Abbreviations and Acronyms \\ ICU = intensive care unit \\ NPWT $=$ negative-pressure wound therapy}

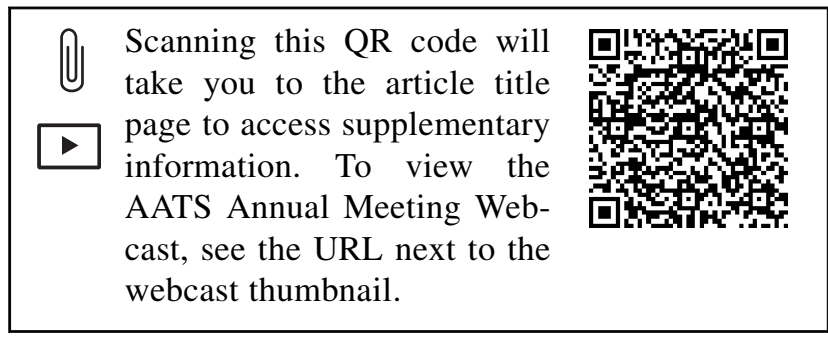

In 2009, negative-pressure wound therapy (NPWT) was introduced to noninfected open-chest management after cardiac surgery at our institution for patients with severe coagulopathy and ongoing bleeding and for patients whose hemodynamics were compromised by sternal closure. NPWT was quickly adopted by our surgeons, reaching nearly $100 \%$ by 2014 (Figure 1).

Argenta and Morykwas ${ }^{1}$ introduced NPWT for treating infected wounds in 1997; since then, managing large surface area wounds with NPWT, infected or not, has gained popularity in many specialties. Although in cardiac surgery it has been used in treating poststernotomy mediastinitis, ${ }^{2-4}$ little is known about its value in managing noninfected open chests in adults. ${ }^{5,6}$ Therefore, the objective of this study was to compare the safety and clinical effectiveness of NPWT with traditional wound therapy for managing noninfected open chests after cardiac surgery.

\section{METHODS \\ Study Population}

From January 2000 to July 2015, 57,890 adults age 18 and older underwent cardiac surgery at Cleveland Clinic. Of these, 54,870 underwent surgery via sternotomy (47,325 full, 7311 hemi, 234 unspecified), 452 $(0.96 \%)$ of whom left the operating room with an open chest, primarily for uncontrolled coagulopathy or hemodynamic compromise, but also for respiratory compromise from pulmonary or mediastinal edema. Of the 452, $214(47 \%)$ were managed with NPWT and 238 (53\%) with traditional wound therapy. This intent-to-treat cohort is the focus of our study.

An additional 136 patients had secondary sternal opening postoperatively for noninfected indications during this time period, $56(41 \%)$ of whom were managed using NPWT and $80(59 \%)$ with traditional wound therapy. This cohort is discussed in Appendix E1.

\section{Open-Chest Management}

NPWT. Our NPWT protocol includes adequately covering cardiovascular structures with a nonadhesive dressing in immediate contact with the heart and placing gauze sponges around the heart to cover bleeding surfaces. A bridge keeps sternal edges separated. On top, a large foam sponge is fitted and the wound sealed with an adhesive dressing containing a central opening for the vacuum adapter, which is connected to a negative-pressure device that is then set to -25 to $-75 \mathrm{~mm} \mathrm{Hg}$. This sucks in the foam sponge, confirming the seal (see Figure 2 and Video 1 for details).

Traditional wound therapy. Traditional open-chest management consists of packing the mediastinum with gauze sponges, inserting a sternal bridge, and suturing or stapling a synthetic membrane, such as Esmarch (Spectrum, Repligen Corp, Waltham, Mass), to skin edges, then applying a sealing adhesive dressing on top.

General principles of open-chest management. Regardless of wound therapy strategy, great care is taken to ensure that the heart, particularly the right ventricle, is not injured by sharp edges of the sternum or by the bridge used to separate sternal edges. In the intensive care unit (ICU), patients are mechanically ventilated and sedated. The first priority is maintaining hemodynamic stability and correcting coagulopathy. Bedside emergency re-exploration is performed as necessary for hemodynamic instability or clot evacuation (for details, see Appendix E2); if the patient is reasonably stable, re-exploration is performed in the operating room, particularly if improved hemostasis is to be attempted. The second priority is achieving good diuresis to obtain negative fluid balance, which decreases myocardial and tissue edema. If the patient is not responding to diuretics, continuous veno-venous hemodialysis is instituted.

Timing of chest closure. The chest is closed when patients' cardiac function and hemodynamics are clinically acceptable and stable, coagulopathy corrected, excess fluid removed, and pulmonary function adequate; in patients with temporary assist devices, myocardial recovery plays a more important role in this decision-making. When conditions are thought to be favorable, the patient is returned to the operating room for sternal closure. The mediastinal protective membrane, sponges, and any clots are removed, followed by generous irrigation and standard wire closure.

\section{Data}

Routine prospective data collection for cardiac surgical patients includes variables in the Society of Thoracic Surgeons Adult Cardiac database $^{7}$ augmented by imaging, laboratory, and electronic medical record databases. In addition, indication for leaving the chest open, details of open-chest management, timing of chest closure, and timing of deaths were abstracted from medical records. Use of these data for research was approved by the institutional review board, with patient consent waived.

\section{End Points}

Safety end points included injury to cardiac structures, re-explorations, and infections during or after open-chest therapy. Clinical effectiveness end points included duration of open-chest management, hemodynamic intolerance, inotropic and vasoconstrictor support, bleeding and transfusions, conversions of one wound therapy to the other, ICU and postoperative lengths of stay, and death. Median follow-up among NPWT survivors was 1.3 years, with $25 \%$ followed more than 4 years and $10 \%$ more than 6 years. For survivors of traditional wound therapy, these follow-up numbers were 4.6 years, 7 years, and 11 years. Survival was assessed nonparametrically using the Kaplan-Meier method and parametrically using a multiphase hazard model. ${ }^{8}$ The latter involved resolving the number of hazard phases for instantaneous risk of death (hazard function) and estimating shaping parameters.

\section{Data Analysis}

Statistical analyses were performed using SAS statistical software version 9.4 (SAS Institute, Cary, NC), and R software version 3.5.0 (The $\mathrm{R}$ Project for Statistical Computing, Vienna, Austria). In general, categorical variables are summarized as frequencies and percentages and continuous variables as mean \pm standard deviation, or as 15th, 50th (median), and 85th percentiles when their distribution was skewed. Comparisons used standardized differences. Because of the number of deaths, median and percentiles for open-chest and mechanical ventilation durations and ICU and postoperative lengths of stay were obtained using the KaplanMeier estimator, censoring at death. Comparisons used the log rank test. 

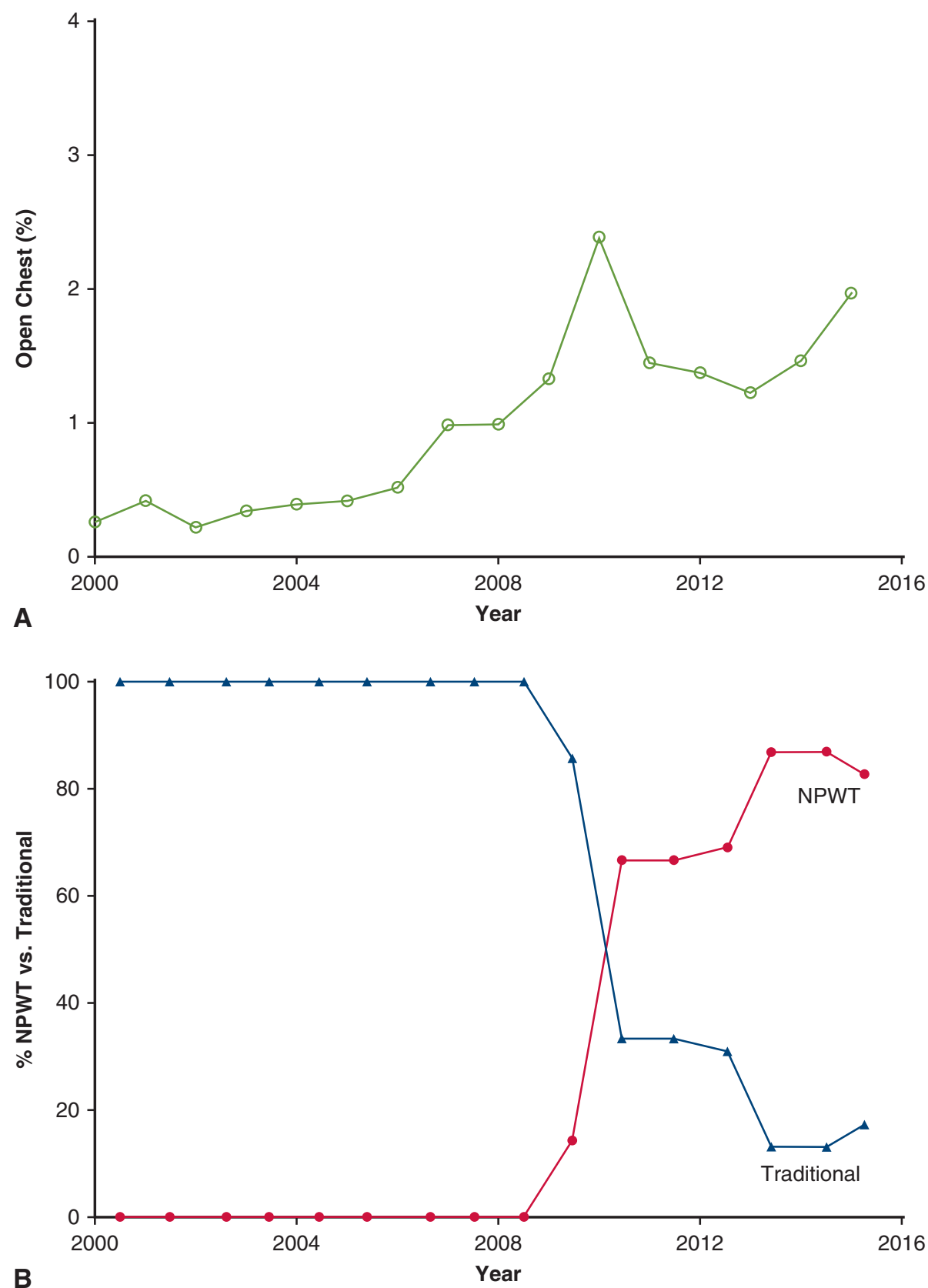

FIGURE 1. Yearly temporal trend in noninfected open-chest management for hemodynamic compromise or coagulopathy during cardiac surgery. A, Prevalence of open chests among patients who underwent full sternotomy across calendar years $(\mathrm{n}=47,325)$. B, Negative-pressure wound therapy (NPWT; red line and closed circles) and traditional wound therapy (blue line and triangles) use across calendar years.

Confidence intervals equivalent to \pm 1 or \pm 2 standard errors are used as appropriate.

\section{Outcomes Analysis}

Because characteristics of patients and their surgery differed between those managed using NPWT versus traditional wound therapy (Table 1), weighted propensity-score matching was used to compare outcomes. ${ }^{9}$ This was a 2-step process: developing the propensity model and using the resulting patient-specific propensity score for weighted matching. In developing the propensity model, we first constructed a parsimonious logistic regression model to identify variables associated with patients receiving NPWT. Variable selection among those listed in Appendix E3 used bootstrap aggregation ${ }^{10-12}$ with automated analysis of 1000 resampled (bootstrap) data sets and a $P$-value criterion for retention of variables in the model of $\leq .05$. This was followed by tabulating the frequency of occurrence of single factors and closely related clusters of factors (aggregation). The final parsimonious model retained variables occurring in $50 \%$ or more of these models $(\mathrm{C}=.75$; Table E2).

To this parsimonious model, we added variables representing patient demographics, comorbidities, laboratory values, hemodynamics, 

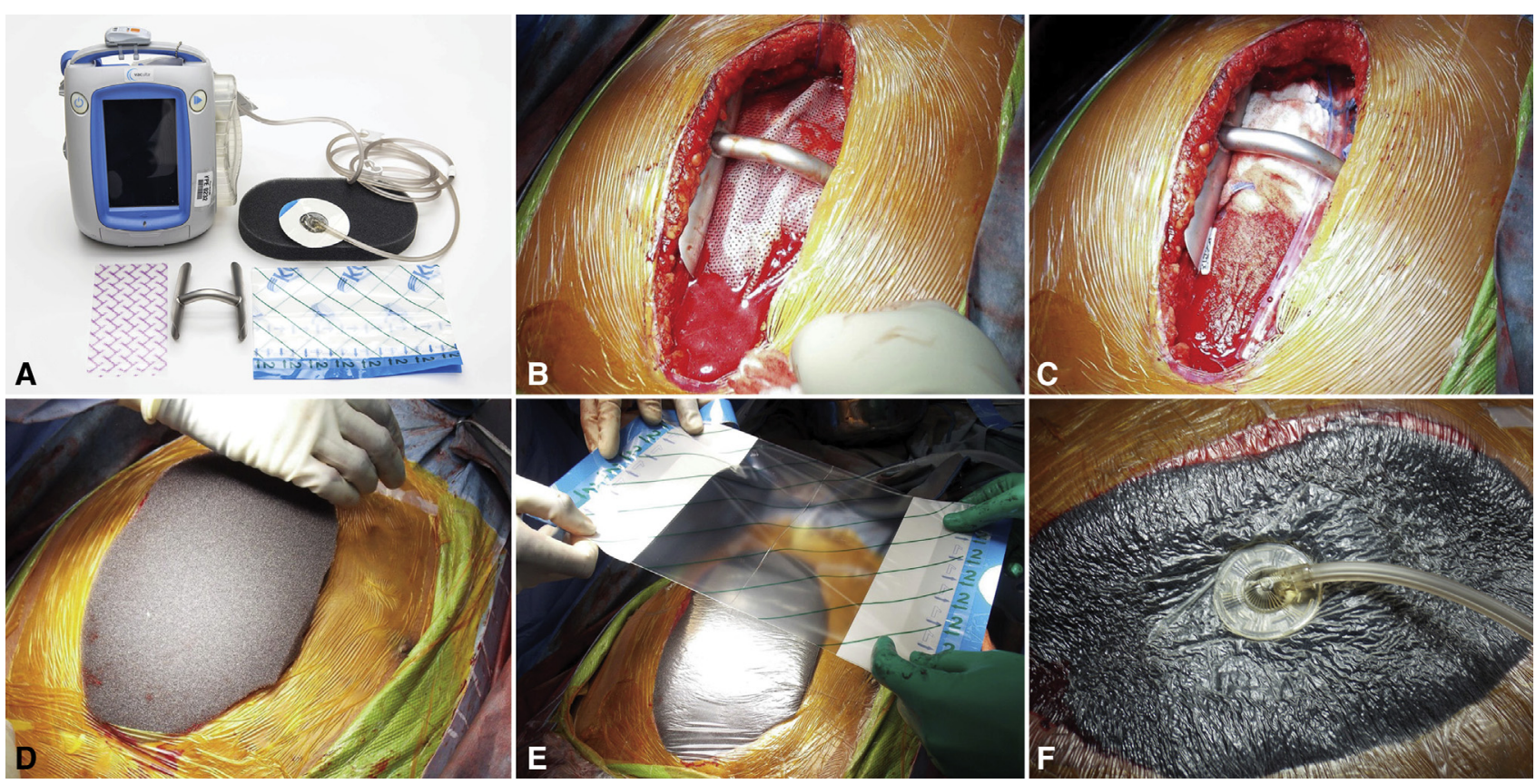

FIGURE 2. Negative-pressure wound therapy (NPWT) uses a nonadhesive dressing (Mepitel, Mölnlycke Health Care, Gothenburg, Sweden), a metal sternal bridge (made at Cleveland Clinic), a vacuum-assisted closure foam sponge, an adhesive dressing, a vacuum adapter, and a suction device. A, Foam, adapter, and suction device (Kinetic Concepts, Inc, San Antonio, Tex). Steps for NPWT installation are as follows. B, Pleural and mediastinal chest tubes are placed as if the patient were to be closed. Sternal borders are kept separated with a metal sternal bridge. A nonadhesive dressing is placed directly on the heart, including bypass grafts for cover and protection. This dressing also protects the heart from direct contact with the sternum and bridge. C, Gauze sponges ( 1 or more) are placed around the heart on top of the nonadhesive dressing to cover raw bleeding surfaces and suture lines. D, A large foam sponge is cut and fitted between the sternal edges. E, The wound is sealed with adhesive film dressing. F, A central 1-cm opening is made and the vacuum adapter is placed on top. The adapter line is connected to the suction device, and the pressure is set to between -25 and $-75 \mathrm{~mm} \mathrm{Hg}$. Tight sealing is confirmed by the foam sponge being sucked in and the negative pressure maintained. A tight seal is crucial for proper NPWT function.

and the procedure that might be related to unrecorded selection factors (semisaturated model) regardless of statistical significance, 52 in all $(\mathrm{C}=.81$; see Appendix E3). A propensity score was calculated for each patient by solving this model for the probability of having NPWT.

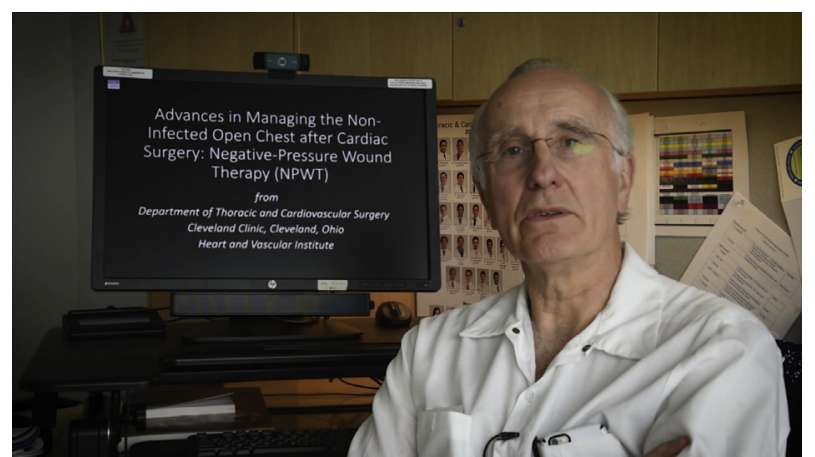

VIDEO 1. This video provides an introduction to the article, including the rationale for using negative-pressure wound therapy (NPWT) for open-chest management and the reason it was quickly adopted by all of our surgeons. NPWT facilitates wound management and reduces the need for chest reexplorations without adding new complications. The video also provides an illustrated description of the steps of application. NPWT is currently our recommended strategy for managing open chests. Video available at: https://www.jtcvs.org/article/S0022-5223(18)33144-1/fulltext.
We then used the propensity-weighting analogue to pair-matching developed by Li and Greene" using the CRAN R package "PSW" (The $\mathrm{R}$ Project for Statistical Computing). The sum of weights for each therapy is the effective sample size. Asymptotically, it will be identical for the 2 groups but not a whole number; because of the finite number of patients, effective sample sizes of the 2 propensity-weighted groups were numerically close. This resulted in generally close matching except for intraoperative blood use (Figure E1). Outcomes between propensityweighted groups were compared using either weighted logistic regression or weighted time-to-event analysis to estimate the treatment effect. To correctly estimate variance of the treatment effect and take into account uncertainty in the estimated propensity score, the bootstrap method was used.

\section{Missing Data}

To account for missing values for some variables, fivefold multiple imputation was performed using multivariate imputation by chained equations (MICE, SAS PROC MI; SAS Institute). Variable selection used 1 of these imputations. Regression coefficients for final model variables and their variance-covariance matrix were estimated for each imputed data set and combined using the method described by Rubin. ${ }^{13}$

\section{RESULTS \\ Patient Profiles}

Among the 452 open-chest patients, 267 were men $(59 \%)$ and 185 women $(41 \%)$; mean age was 
TABLE 1. Patient characteristics and operative details

\begin{tabular}{|c|c|c|c|c|c|c|c|c|c|c|}
\hline \multirow[b]{3}{*}{ Variable } & \multicolumn{5}{|c|}{ Before matching } & \multicolumn{5}{|c|}{ Weighted-matched } \\
\hline & \multicolumn{2}{|r|}{$\begin{array}{c}\text { NPWT } \\
(n=214)\end{array}$} & \multicolumn{2}{|c|}{$\begin{array}{c}\text { Traditional } \\
(\mathbf{n}=\mathbf{2 3 8})\end{array}$} & \multirow{2}{*}{$\begin{array}{c}\begin{array}{c}\text { Standardized } \\
\text { difference }\end{array} \\
\%\end{array}$} & \multicolumn{2}{|c|}{$\begin{array}{c}\text { NPWT } \\
(\mathrm{n}=119.5)\end{array}$} & \multicolumn{2}{|c|}{$\begin{array}{l}\text { Traditional } \\
(\mathrm{n}=123.7)\end{array}$} & \multirow{2}{*}{$\begin{array}{c}\begin{array}{c}\text { Standardized } \\
\text { difference }\end{array} \\
\%\end{array}$} \\
\hline & $\overline{\mathbf{n}^{*}}$ & Value & $\bar{n} *$ & Value & & $\overline{n^{*}}$ & Value & $\overline{n *}$ & Value & \\
\hline \multicolumn{11}{|l|}{ Demographics } \\
\hline Age, y & 214 & $64 \pm 14$ & 238 & $64 \pm 14$ & -6.8 & 120 & $64 \pm 14$ & 124 & $64 \pm 13$ & 0.48 \\
\hline Female & 214 & $81(38)$ & 238 & $104(44)$ & -12 & 120 & $47(40)$ & 124 & $50(40)$ & -1.9 \\
\hline Body mass index, $\mathrm{kg} / \mathrm{m}^{2}$ & 214 & $30 \pm 6.6$ & 227 & $29 \pm 6.5$ & 6.1 & 120 & $29 \pm 6.3$ & 119 & $29 \pm 6.4$ & -1.1 \\
\hline \multicolumn{11}{|l|}{ Symptoms } \\
\hline NYHA functional class & 191 & & 235 & & -8.8 & 107 & & 121 & & 1.9 \\
\hline I & & $27(14)$ & & $32(14)$ & & & $15(14)$ & & $20(17)$ & \\
\hline II & & $40(21)$ & & $52(22)$ & & & $23(21)$ & & $38(23)$ & \\
\hline III & & $75(39)$ & & $70(30)$ & & & $40(37)$ & & $33(28)$ & \\
\hline IV & & $49(26)$ & & $81(34)$ & & & $29(28)$ & & $40(33)$ & \\
\hline \multicolumn{11}{|l|}{ Cardiac comorbidity } \\
\hline Emergency operation & 214 & $45(21)$ & 238 & $60(25)$ & -9.2 & 120 & $29(24)$ & 124 & $31(25)$ & -2.8 \\
\hline Previous MI & 214 & $80(37)$ & 238 & $120(50)$ & -26 & 120 & $49(41)$ & 124 & $50(41)$ & 1.0 \\
\hline Atrial fibrillation or flutter & 209 & $60(29)$ & 220 & $34(15)$ & 32 & 117 & $26(22)$ & 115 & $23(20)$ & 4.9 \\
\hline Complete heart block/pacer & 209 & $11(5.3)$ & 220 & $28(13)$ & -26 & 117 & $7.6(6.5)$ & 115 & $7.7(6.7)$ & -0.69 \\
\hline Previous cardiac operations & 214 & & 238 & & 11 & 120 & & 124 & & -0.94 \\
\hline 0 & & $79(37)$ & & $103(43)$ & & & $51(43)$ & & $53(43)$ & \\
\hline 1 & & $86(40)$ & & $85(36)$ & & & $43(36)$ & & $44(36)$ & \\
\hline 2 & & $31(14)$ & & $36(15)$ & & & $19(16)$ & & $20(16)$ & \\
\hline 3 or more & & $18(8.4)$ & & $13(5.5)$ & & & $6.6(5.8)$ & & $6.7(5.4)$ & \\
\hline LVEF, \% & 205 & $45 \pm 16$ & 231 & $43 \pm 18$ & 12 & 115 & $44 \pm 16$ & 120 & $44 \pm 16$ & -0.85 \\
\hline Cardiac index, $\mathrm{L} / \mathrm{min} / \mathrm{m}^{2}$ & 152 & $1.4 / 2.0 / 2.6$ & 183 & $1.3 / 2.1 / 2.7$ & -13 & 86 & $1.9 \pm 0.74$ & 98 & $1.84 \pm 1.0$ & 4.9 \\
\hline Anticoagulation & 205 & $92(45)$ & 221 & $83(38)$ & 15 & 113 & $39(35)$ & 118 & $43(37)$ & -3.8 \\
\hline Aspirin & & $49(23)$ & & $52(22)$ & & & $23(19)$ & & $27(21)$ & \\
\hline Warfarin & & $34(16)$ & & $23(9.7)$ & & & $12(10)$ & & $14(11)$ & \\
\hline Clopidogrel & & $8(3.7)$ & & $9(3.8)$ & & & $4.9(4.1)$ & & $4.8(3.9)$ & \\
\hline Other & & $16(7.5)$ & & $20(8.4)$ & & & $6.9(5.7)$ & & $9.2(7.4)$ & \\
\hline \multicolumn{11}{|l|}{ Noncardiac comorbidity } \\
\hline Smoking history & 212 & $113(53)$ & 236 & $146(62)$ & -17 & 118 & $70(59)$ & 123 & $73(59)$ & -0.29 \\
\hline COPD & 214 & $76(36)$ & 238 & $65(27)$ & 17 & 120 & $33(27)$ & 123 & $34(28)$ & -0.54 \\
\hline $\begin{array}{l}\text { Pharmacologically treated } \\
\text { diabetes }\end{array}$ & 211 & $62(29)$ & 231 & $74(32)$ & -5.8 & 118 & $41(34)$ & 120 & $40(33)$ & 2.8 \\
\hline Hypertension & 214 & $183(86)$ & 238 & $183(77)$ & 21 & 120 & $99(83)$ & 123 & $102(83)$ & -0.07 \\
\hline PAD & 214 & $67(31)$ & 238 & $44(18)$ & 30 & 120 & $27(22)$ & 123 & $28(23)$ & -0.42 \\
\hline Creatinine, $\mathrm{mg} / \mathrm{dL}$ & 214 & $0.77 / 1.2 / 2.2$ & 236 & $0.80 / 1.2 / 2.0$ & 9.2 & 120 & $0.76 / 1.1 / 2.0$ & 122 & $0.83 / 1.2 / 1.9$ & -2.1 \\
\hline Bilirubin, $\mathrm{mg} / \mathrm{dL}$ & 213 & $0.40 / 0.60 / 1.4$ & 229 & $0.40 / 0.70 / 1.6$ & -6.2 & 119 & $0.40 / 0.60 / 1.4$ & 119 & $0.30 / 0.60 / 1.5$ & -1.4 \\
\hline \multicolumn{11}{|l|}{ Index procedure } \\
\hline CABG & 214 & $96(45)$ & 238 & $120(51)$ & -12 & 120 & $56(47)$ & 124 & $57(46)$ & 1.3 \\
\hline \multicolumn{11}{|l|}{ Valve operation } \\
\hline Aortic & 214 & $123(57)$ & 238 & $119(50)$ & 15 & 120 & $64(54)$ & 124 & $67(54)$ & -0.47 \\
\hline Mitral & 214 & $83(39)$ & 238 & $83(35)$ & 7.8 & 120 & $41(34)$ & 124 & $42(34)$ & 0.97 \\
\hline Tricuspid & 214 & $36(17)$ & 238 & $47(20)$ & -7.6 & 120 & $20(17)$ & 124 & $21(17)$ & -0.34 \\
\hline Heart transplant & 214 & $7(3.3)$ & 238 & $17(7.1)$ & -17 & 120 & $5.1(4.2)$ & 124 & $5.2(4.2)$ & 0.14 \\
\hline Aortic surgery & 214 & $102(48)$ & 238 & $75(32)$ & 33 & 120 & $47(39)$ & 124 & $50(41)$ & -2.4 \\
\hline \multicolumn{11}{|l|}{ Perfusion details } \\
\hline CPB time, minutes & 214 & $131 / 215 / 315$ & 238 & $122 / 183 / 280$ & 28 & 120 & $119 / 196 / 298$ & 123 & $127 / 191 / 301$ & 0.84 \\
\hline $\begin{array}{l}\text { Myocardial ischemic } \\
\text { time, minutes }\end{array}$ & 214 & $45 / 136 / 214$ & 238 & $41 / 106 / 172$ & 36 & 120 & $32 / 122 / 181$ & 123 & $53 / 120 / 187$ & -1.7 \\
\hline
\end{tabular}


TABLE 1. Continued

\begin{tabular}{|c|c|c|c|c|c|c|c|c|c|c|}
\hline \multirow[b]{3}{*}{ Variable } & \multicolumn{5}{|c|}{ Before matching } & \multicolumn{5}{|c|}{ Weighted-matched } \\
\hline & \multicolumn{2}{|c|}{$\begin{array}{c}\text { NPWT } \\
(n=214)\end{array}$} & \multicolumn{2}{|c|}{$\begin{array}{c}\text { Traditional } \\
(\mathbf{n}=\mathbf{2 3 8})\end{array}$} & \multirow{2}{*}{$\begin{array}{c}\begin{array}{c}\text { Standardized } \\
\text { difference }\end{array} \\
\% \\
\end{array}$} & \multicolumn{2}{|c|}{$\begin{array}{c}\text { NPWT } \\
(n=119.5)\end{array}$} & \multicolumn{2}{|c|}{$\begin{array}{l}\text { Traditional } \\
(\mathrm{n}=123.7)\end{array}$} & \multirow{2}{*}{ 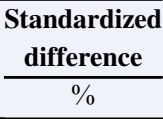 } \\
\hline & $\bar{n} *$ & Value & $\overline{\mathbf{n}^{*}}$ & Value & & $\overline{\mathbf{n}^{*}}$ & Value & $\overline{\mathbf{n}^{*}}$ & Value & \\
\hline \multicolumn{11}{|l|}{$\begin{array}{c}\text { Intraoperative blood } \\
\text { products, } \mathrm{U}\end{array}$} \\
\hline Red blood cells & 214 & $3 / 7 / 13$ & 187 & $2 / 7 / 15$ & -16 & 120 & $2 / 6 / 12$ & 102 & $2 / 6 / 14$ & -12 \\
\hline Platelets & 214 & $1 / 3 / 4$ & 187 & $1 / 3 / 6$ & -14 & 120 & $1 / 3 / 4$ & 102 & $1 / 3 / 5$ & -8.0 \\
\hline Fresh frozen plasma & 214 & $2 / 5 / 11$ & 187 & $1 / 5 / 12$ & -5.0 & 120 & $1 / 5 / 10$ & 102 & $1 / 5 / 11$ & -8.6 \\
\hline Indication for open chest & 214 & & 238 & & & 120 & & 124 & & \\
\hline Coagulopathy & & $71(33)$ & & $84(35)$ & -4.5 & & $47(39)$ & & $44(35)$ & 7.3 \\
\hline $\begin{array}{r}\text { Hemodynamic } \\
\text { compromise }\end{array}$ & & $46(21)$ & & $81(34)$ & -28 & & $30(25)$ & & $35(28)$ & -6.6 \\
\hline Both & & $87(41)$ & & $48(20)$ & 45 & & $35(30)$ & & $35(28)$ & 2.7 \\
\hline Other & & $10(4.7)$ & & $25(11)$ & -22 & & $7.1(6.0)$ & & $9.6(7.8)$ & -7.2 \\
\hline
\end{tabular}

Data are presented as No. (\%), mean $\pm \mathrm{SD}$, or 15th/50th/85th percentiles. NPWT, Negative-pressure wound therapy; $N Y H A$, New York Heart Association; $M I$, myocardial infarction; $L V E F$, left ventricular ejection fraction; $C O P D$, chronic obstructive pulmonary disease; $P A D$, peripheral arterial disease; $C A B G$, coronary artery bypass grafting; $C P B$, cardiopulmonary bypass. *Patients with data available.

$64 \pm 13$ years (Table 1). Baseline patient profile was generally high-risk in both wound therapy groups, with peripheral arterial disease $(31 \%$ vs $18 \%)$, hypertension $(86 \%$ vs $77 \%)$, preoperative atrial fibrillation $(29 \%$ vs $15 \%)$, and chronic obstructive pulmonary disease ( $36 \%$ vs $27 \%$ ) more common in the NPWT group, and previous myocardial infarction (37\% vs 50\%) and complete heart block $(5.3 \%$ vs $13 \%)$ more common in the traditional wound therapy group. Many patients, $45 \%$ in the NPWT group and $38 \%$ in the traditional wound therapy group, came to surgery using platelet inhibitors or warfarin. Most operations were reoperations, $63 \%$ and $57 \%$ of patients receiving NPWT or traditional wound therapy, respectively, and $21 \%$ versus $25 \%$ were emergency procedures. More patients in the NPWT group than in the traditional wound therapy group underwent thoracic aorta operations, 102 $(48 \%)$ versus $75(32 \%)$, respectively. Cardiopulmonary bypass and ischemic times were longer in the NPWT group.

\section{Events During Open-Chest Management}

A similar majority of patients in both groups left the operating room receiving multiple inotropic drugs and vasoconstrictors, balloon counterpulsation, extracorporeal membrane oxygenation, or mechanical circulatory support (Table 2). Inotrope and vasoconstrictor use was high through 48 hours postoperatively using multiple drugs, but with a tendency toward more use of vasopressin with NPWT. Methylene blue was rarely used.

Fewer patients in the NPWT group had ICU bedside explorations for bleeding or hemodynamic compromise than in the traditional wound therapy group $(13 \%$ vs $29 \%$; $P=.0009$ ), total bedside explorations and take-backs to the operating room for bleeding/tamponade were also less frequent $(29 \%$ vs $44 \% ; P=.002)$, and fewer blood products were used postoperatively (Table 2, Figure E2, A). Approximately half of the patients with both therapies underwent elective dressing changes for loss of seal or other issues. For NPWT patients, dressing change often included replacing the foam sponge.

Duration of open chest was slightly longer with NPWT, median 3.5 days (15th and 18th percentiles, 2.0-8.0), than with traditional wound therapy, median 3.1 days (15th and 18th percentiles, 1.6-7.1) $(P=.07$; Figure 3$)$. Duration of ventilation was longer in the NPWT group than in the traditional wound therapy group $(P=.005$; Figure $\mathrm{E} 3, A)$, as was use of tracheostomy $(P<.0001)$, which increased with time (Figure E2, $B$ ).

\section{Outcomes (Propensity-Weighted Matched Groups)}

No cardiac, graft, or vascular injuries occurred in either group. Seven patients $(3.3 \%)$ were converted from NPWT to traditional wound therapy and $6(2.5 \%)$ from traditional to NPWT. One indication for conversion from NPWT was hemodynamic compromise-relieved by removing the negative pressure-but indication in individual cases was poorly documented.

Among propensity-weighted matched groups, the NPWT group received fewer blood products overall (Table 3). Although apparently fewer patients in the NPWT group experienced infections than in the traditional wound therapy group, there was an abrupt decrease in infections when all cardiac services were moved into a new building in 2008 (Figure E2, C), after which NPWT was initiated. After 2008, the traditional wound therapy group experienced a similar low risk of infection (Table E3).

Duration of mechanical ventilation was not longer (Figure E3, B), but use of tracheostomy was greater in the NPWT group than in the traditional wound therapy group 
TABLE 2. Management and events during open-chest wound therapy

\begin{tabular}{|c|c|c|c|c|}
\hline \multirow[b]{2}{*}{ Variable } & \multicolumn{2}{|c|}{ NPWT $(n=214)$} & \multicolumn{2}{|c|}{$\begin{array}{l}\text { Traditional wound } \\
\text { therapy }(n=238)\end{array}$} \\
\hline & n* & Value & $\mathbf{n}^{*}$ & Value \\
\hline Inotropes and vasopressors $\dagger$ & 212 & & 229 & \\
\hline At $12 \mathrm{~h}$ & & $195(92)$ & & $211(92)$ \\
\hline At $24 \mathrm{~h}$ & & $189(89)$ & & $206(90)$ \\
\hline At $48 \mathrm{~h}$ & & $181(86)$ & & $183(83)$ \\
\hline Mechanical circulatory support during or after surgery & 214 & $112(52)$ & 236 & $130(55)$ \\
\hline ECMO & & $65(31)$ & & $60(26)$ \\
\hline Left ventricular assist device & & $18(8.4)$ & & $27(11)$ \\
\hline Intra-aortic balloon pump & & $67(32)$ & & $72(31)$ \\
\hline Dialysis & 213 & $89(42)$ & 229 & $92(40)$ \\
\hline Bedside re-explorations & 209 & & 226 & \\
\hline 0 & & $181(87)$ & & $160(71)$ \\
\hline 1 & & $23(11)$ & & $45(20)$ \\
\hline 2 & & $3(1.4)$ & & $17(7.5)$ \\
\hline 3 & & $2(0.96)$ & & $3(1.3)$ \\
\hline 4 & & $0(0)$ & & $1(0.44)$ \\
\hline \multicolumn{5}{|l|}{ Indication for bedside or OR re-exploration during open-chest management } \\
\hline Bleeding/tamponade & & $20(9.3)$ & & $40(17)$ \\
\hline Cardiac & & $12(5.6)$ & & $18(7.6)$ \\
\hline Both & & $26(12)$ & & $41(17)$ \\
\hline Re-exploration (ICU) or take-back to OR for bleeding any time postoperatively & & $63(29)$ & & $104(44)$ \\
\hline \multicolumn{5}{|l|}{ Blood products used postoperatively, $\mathrm{U}$} \\
\hline Red blood cells & 214 & $8 / 16 / 31$ & 231 & $8 / 17 / 35$ \\
\hline Platelets & 214 & $3 / 7 / 16$ & 231 & $4 / 13 / 30$ \\
\hline Fresh frozen plasma & 214 & $4 / 9 / 19$ & 237 & $4 / 12 / 26$ \\
\hline Cryoprecipitate & 214 & $0.25 / 4 / 10$ & 237 & $0 / 3 / 20$ \\
\hline \multicolumn{5}{|l|}{ Respiratory management } \\
\hline Duration of mechanical ventilation, $\mathrm{d} \ddagger$ & 200 & $4.0 / 13 / 40$ & 215 & $3.2 / 9.0 / 30$ \\
\hline Tracheostomy & 211 & $83(39)$ & 231 & $44(19)$ \\
\hline
\end{tabular}

Data are presented as No. (\%) or 15th/50th/85th percentiles. $N P W T$, Negative-pressure wound therapy; $E C M O$, extracorporeal membrane oxygenation; $O R$, operating room; $I C U$, intensive care unit. *Patients with data available. †Epinephrine, milrinone, norepinephrine, vasopressin, phenylephrine, methylene blue. †Estimates from actuarial curve.

(Table 3). ICU and postoperative lengths of stay were longer in the NPWT group (Figure E4).

Among propensity-weighted matched groups, hospital mortality was high, $33 \%$ in the NPWT group and $46 \%$ in the traditional wound therapy group $(P=.03$; Table 3$)$. Median time to hospital death was 142 hours (range, 15-743) in the NPWT group and 89 hours (range, 10-483) in the traditional wound therapy group $(P=.3)$. Both groups experienced a high, sharply decreasing early instantaneous risk of death that was lower in the NPWT group $(P=.02$; Figure 4, $A$; hazard phases, Figure E5). It fell to a prolonged late hazard phase by approximately 3 months, similar in both wound therapy groups ( $P=.4$; inset, Figure $4, A$; hazard phases, Figure E5). This resulted in survival at 30 days, 6 months, and 1 and 5 years of $70 \%, 61 \%, 57 \%$, and $45 \%$ in the NPWT group and $55 \%, 44 \%, 41 \%$, and $30 \%$ in the traditional wound therapy group (Figure $4, B$ ).

\section{DISCUSSION}

\section{Principal Findings}

Our study describes, to our knowledge, the largest population reported to date of adult patients receiving noninfected open-chest management after cardiac surgery. Our rationale for starting to use NPWT was to reduce risk of tamponade and take-backs for bleeding. Impressed by its apparent safety and effectiveness, our surgeons quickly adopted it, and subsequently NPWT was also used for managing patients with hemodynamic compromise evident at sternal closure. As shown by this study, NPWT was as safe as traditional wound management, with no cardiac injuries. Compared with patients who had traditional openchest management, NPWT patients experienced fewer bedside explorations and reoperations for bleeding, fewer blood product transfusions, and had better time-related survival. Patients whose chests were opened secondarily after 


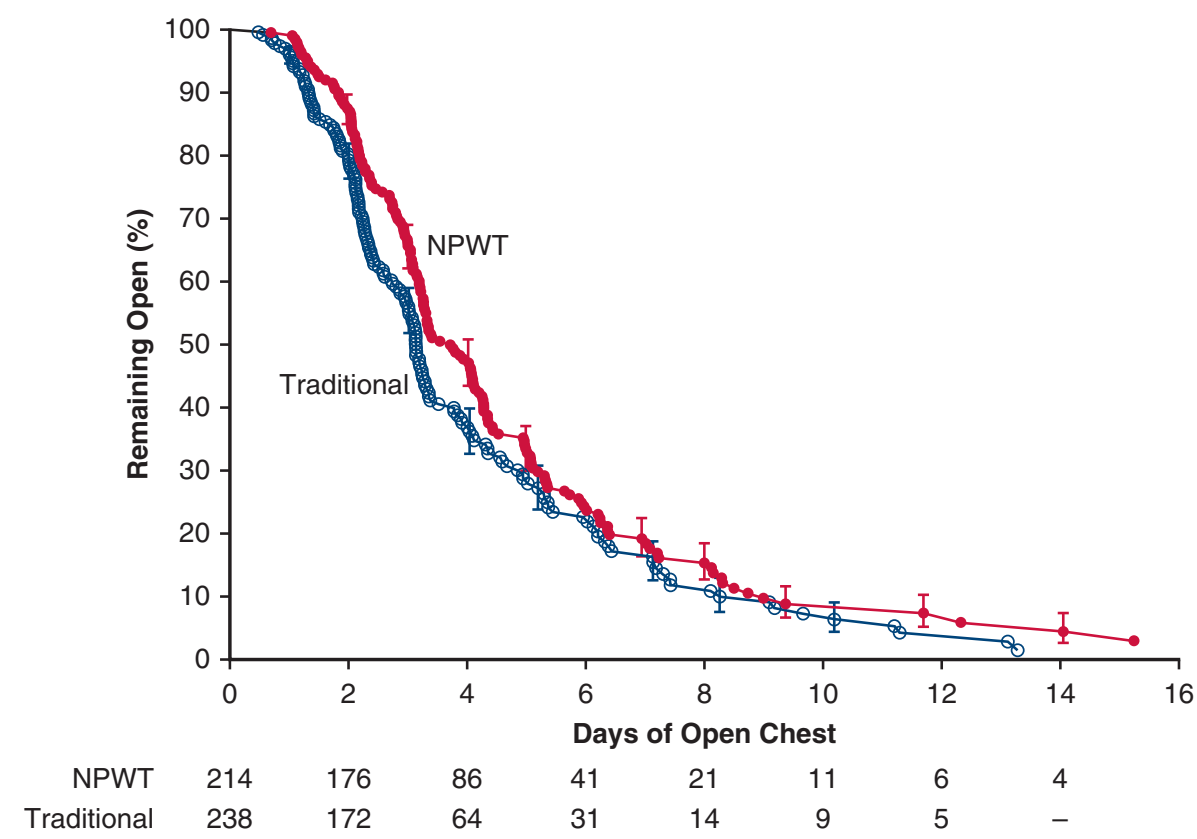

FIGURE 3. Duration of open-chest wound therapy according to wound management, with duration presented actuarially, censored at patient death during the episode of open-chest therapy. Red closed circles and line denote negative-pressure wound therapy (NPWT) and blue open circles and line traditional wound therapy. Vertical bars represent $68 \%$ confidence limits equivalent to \pm 1 standard error.

primary closure in the operating room experienced somewhat worse outcomes (Appendix E1).

\section{Rationale for Leaving the Chest Open}

The rationale for leaving the chest open is to treat (1) hemodynamic compromise after the cardiac operation and (2) uncontrolled coagulopathy. When sternal closure results in important decreases in diastolic filling and cardiac output despite preserved cardiac contractility, ${ }^{14}$ reopening the sternum increases cardiac output and systolic blood pressure. ${ }^{15,16}$ This becomes more important when cardiac function is reduced and the heart is large and edematous after a long operation, which invites leaving the sternotomy open.

Riahi and colleagues ${ }^{17}$ were the first to diagnose and treat "tight mediastinal syndrome" in 1975, with the sternum closed using an external traction device connected to the sternal wires to increase the anteroposterior mediastinal diameter. Then in 1978, Ott and colleagues ${ }^{18}$ first reported a series of 4 patients treated with open-chest management using delayed sternal closure because of intractable bleeding and ventricular distension. Thereafter, multiple groups reported adopting the technique and applying it for broader indications, including intractable arrhythmias and insertion of temporary assist devices. ${ }^{14-16,19-23}$ Many studies report meaningful survival and low occurrence of mediastinitis. ${ }^{19,21}$

\section{Open-Chest Management}

Our overall prevalence of open chest of $0.96 \%$ during the study period is consistent with the adult cardiac surgery literature. ${ }^{14-16,19,22-25}$ The complexity of patients and operations performed at our institution has increased over time,${ }^{26}$ and this has likely contributed to the increased number of open chests. However, the perceived benefits of NPWT have contributed to lowering our threshold to leave the sternotomy open.

Various protocols for maintaining an open sternum have been used, including mediastinal packing, self-retaining retractors, closing only the skin, adhesive drape film coverage, and latex membrane coverage. ${ }^{16,21}$ Direct skin approximation and closure is a logical approach, but is often not possible. Use of adhesive drape film might not completely seal the wound and is easily detached by active bleeding. Covering the open mediastinum with a latex membrane sewn to the skin edges carries the disadvantages of damaging the skin through repeated re-explorations, revisions, and loss of sterility. Sterility is lost when dressings leak from ongoing bleeding, raising concern about infectious complications when the chest is left open for prolonged periods. Through the airtight sealing of the wound in NPWT, contamination is actively prevented. ${ }^{27,28}$

NPWT for managing the open noninfected chest came about through therapy for mediastinitis. ${ }^{2}$ Experimentally, Sjogren and colleagues ${ }^{28}$ applied different negative pressures $(-50$ to $-175 \mathrm{~mm} \mathrm{Hg}$ ) to open sternotomies in pigs for 30 minutes while hemodynamics were measured. They showed that negative-pressure closure at these negative pressures did not impair central hemodynamics. Fleck 
TABLE 3. In-hospital morbidity, mortality, and lengths of stay among weighted-matched patients

\begin{tabular}{|c|c|c|c|}
\hline Outcome & $\frac{\text { NPWT }(n=119.5)}{\text { No.* }(\%) \text { or } 15 \text { th } / 50 \text { th/85th percentiles }}$ & $\frac{\text { Traditional wound therapy }(\mathrm{n}=123.7)}{\text { No.* }(\%) \text { or } 15 \text { th/50th/85th percentiles }}$ & $\boldsymbol{P}$ \\
\hline Cardiac, graft, or vascular injury & $0(0)$ & $0(0)$ & - \\
\hline Infectious $\dagger$ & $20(17)$ & $30(24)$ & .13 \\
\hline Septicemia & $14(12)$ & $22(18)$ & .19 \\
\hline Mediastinitis & $2.4(2.0)$ & $6.0(4.9)$ & .2 \\
\hline Pneumonia & $8.8 / 114(7.7)$ & $16 / 119(13)$ & .16 \\
\hline Stroke & $7.2(6.1)$ & $6.9(5.6)$ & .9 \\
\hline \multicolumn{4}{|l|}{ Blood products used, $\mathrm{U}$} \\
\hline Red blood cells & $7 / 15 / 28$ & $8 / 17 / 34$ & .06 \\
\hline Platelets & $3 / 7 / 17$ & $4 / 11 / 26$ & .01 \\
\hline Fresh frozen plasma & $3 / 9 / 16$ & $4 / 11 / 26$ & .06 \\
\hline Atrial fibrillation & $43(36)$ & $36(30)$ & .3 \\
\hline Renal failure & $56(47)$ & $59(48)$ & .9 \\
\hline Dialysis $\ddagger$ & $40(33)$ & $41(33)$ & .9 \\
\hline \multicolumn{4}{|l|}{ Respiratory management } \\
\hline Duration of mechanical ventilation, $\mathrm{d}_{\uparrow}$ & $4.3 / 12 / 40$ & $3.7 / 8.1 / 22$ & .3 \\
\hline Tracheostomy & $47 / 118(40)$ & $24 / 119(20)$ & .0009 \\
\hline \multicolumn{4}{|l|}{ Length of stay $\ddagger$} \\
\hline Intensive care unit, $\mathrm{h}$ & $5.7 / 17 / 43$ & $6.7 / 13 / 28$ & .9 \\
\hline Postoperative, $\mathrm{d}$ & $14 / 23 / 50$ & $13 / 20 / 54$ & .9 \\
\hline Hospital mortality & $39(33)$ & $57(46)$ & .03 \\
\hline
\end{tabular}

NPWT, Negative-pressure wound therapy. *Propensity-weighted number of patients. $\dagger$ Combined outcome of sepsis, sternal wound infection, and pneumonia. $\ddagger$ Estimates from actuarial curve.

and colleagues ${ }^{3}$ studied the effect of NPWT on 22 patients with open chests after cardiac surgery. In 4 patients, NPWT was instituted during the primary operation and in the others after mediastinal re-exploration (mean of 5 days postoperatively). Mortality was $45 \%$ (10 of 22 ), with no occurrence of mediastinitis or NPWT-associated complications. NPWT had no deleterious effect on cardiac hemodynamics or respiratory mechanics, and by stabilizing the thoracic cage, they concluded that nursing and respiratory care were facilitated, with reduced risk of pneumonia.

\section{Potential Risks and Complications of NPWT}

When using NPWT in infected patients, several series have reported devastating complications, such as massive bleeding and right ventricular rupture, ${ }^{29,30}$ although this has also been reported to occur during traditional wound therapy. ${ }^{31,32}$ Malmsjö and colleagues ${ }^{29}$ reported altered position of the heart during NPWT in a pig model and showed that the sharp sternal edges jutted into the right ventricle; they concluded that this might be the reason for heart rupture during NPWT. In our series, with our protocol and safeguards, no cardiac or vascular injury related to NPWT was observed. This mirrors reports from Fleck and colleagues $^{3}$ and others. ${ }^{5,6}$ However, the potential for such injuries is a call for careful and proper application of NPWT, with adequate interface dressing and avoidance of direct mechanical pressure to the surface of the right ventricle or friction with raw sternal edges.

The negative-pressure setting might also be important to safety, but this has not been well studied. Our pressure setting of -25 to $-75 \mathrm{~mm} \mathrm{Hg}$ is lower than that reported for use of NPWT for infected wounds and seems to be safe.

In the vast majority of cases, NPWT has been hemodynamically well tolerated even when the heart was large, edematous, and the ventricles dysfunctional. Crossovers from NPWT to traditional wound therapy and vice versa were few, but the reasons were poorly documented. Even lacking documentation, the most likely reason to remove negative pressure is the suspicion that it is adversely affecting cardiac function and hemodynamics. In a few cases, hemodynamic intolerance related to right ventricular immobilization was immediately noticed in the operating room, and occasional cases like this might not have been recorded as initial NPWT and crossover. In other cases, intolerance is subtle and hemodynamic response to removing the negative pressure remains questionable.

When we adopted NPWT, occurrence of infection did not increase, probably because NPWT turns an open wound into a sealed one, limiting the chance of outside contamination. ${ }^{27,28}$ Occurrence of local and systemic infections was low, despite long bypass times in both the NPWT and traditional wound therapy groups. This contrasts with the 


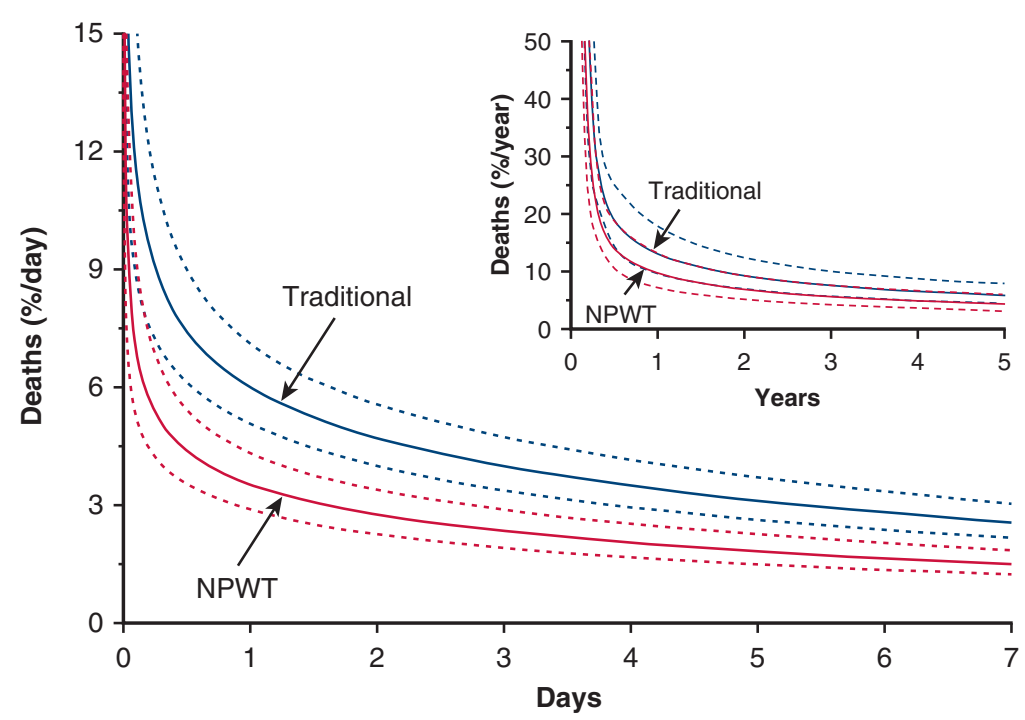

\section{A}

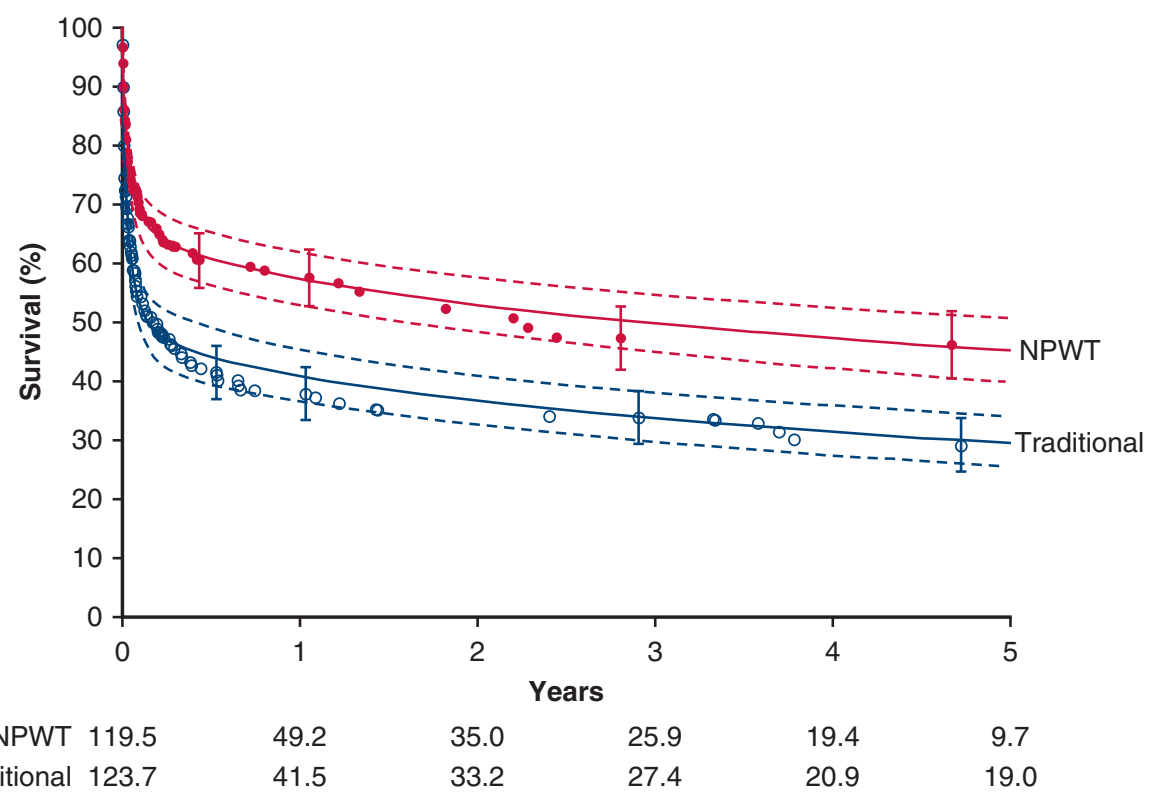

B

FIGURE 4. Mortality according to open-chest management strategy among propensity-weighted matched groups. A, Instantaneous risk of death (hazard function) according to negative-pressure wound therapy (NPWT) and traditional wound therapy. Solid lines represent parametric estimates enclosed within a $68 \%$ confidence band equivalent to \pm 1 standard error. Inset is hazard function to 5 years. B, Survival to 5 years. Each symbol represents a death positioned according to the Kaplan-Meier estimator, periodically accompanied by $68 \%$ confidence limits equivalent to \pm 1 standard error. Solid lines represent parametric survival estimates enclosed within a $68 \%$ confidence band. Nonoverlapping $68 \%$ confidence intervals indicate a difference of at least $P<.07$. Numbers of patients at risk represent effective sample size by propensity-weighted analysis that results in "fractional people."

finding of Matros and colleagues ${ }^{33}$ that prolonged cardiopulmonary bypass was a risk factor for developing mediastinitis. However, occurrence of infections is still higher in patients with open chests than expected for the general cardiac surgery population. In addition to better seal of the wound, another explanation for NPWT patients having somewhat fewer infections than those who receive traditional wound therapy is that they required fewer bedside explorations and reoperations. The traditional wound therapy group also received more blood products than the NPWT group and, although not supported by data from the present study, transfusion of blood products has been associated with risk of infection. ${ }^{34,35}$ Less use of blood products in the NPWT group might be in part because of overall better management of coagulopathy and blood product conservation in recent years (Figure E3, A). 


\section{Mortality}

Previously reported mortality in noninfected openchest management patients ranges from $21 \%$ to $52 \% .{ }^{14-16,19,22,23,25}$ Our mortality was within that range, with better results in the NPWT group. Despite the high proportion of high-risk patients and reoperations, we believe that we are achieving better survival now than in the past. The survival benefits of NPWT extend beyond discharge from the hospital, suggesting that there is a price paid for every additional adverse event the patient experiences during and after cardiac surgery. The fact that patients who were closed primarily but had to be opened later had somewhat poorer outcomes further supports this point (Figure E6).

\section{Clinical Implications}

NPWT is our recommended open-chest management. Beyond occasional patients in whom it is not hemodynamically tolerated, we have identified no contraindications. Because slightly increased duration of wound therapy has not been accompanied by increased occurrence of infection, there is no rush to close the chest before the patient's condition is optimized.

\section{Limitations}

This was a retrospective study subject to biases that might not be fully adjusted for. The early perception of safety and effectiveness quickly suggested superiority of NPWT over traditional wound therapy. It could be argued that this might be a time effect, because the 2 groups were not treated completely concurrently, with most of the traditional therapy group treated earlier than the NPWT group. The perceived benefits of NPWT might have lowered our threshold for leaving the chest open during the study period. It is likely that we do many other things better today, but it is not possible to negate a positive effect of NPWT on outcomes. Our capture of NPWT intolerance and conversions from NPWT to traditional wound therapy might be incomplete because immediate intolerance to NPWT in the operating room might not always have been recorded. The effects of the move to the new building and other measures to prevent infection in 2008, plus introduction of stricter blood conservation in 2010, illustrate the effect of confounding factors on outcomes (Figure E2). Finally, there were too few patients with secondary reopening of the chest to compare risk-adjusted or propensity-matched outcomes.

\section{CONCLUSIONS}

NPWT applied to noninfected open chests after cardiac surgery is safe, reduces re-explorations for bleeding and blood product transfusions, and is associated with better survival than traditional wound therapy. By facilitating open-chest management and potentially improving outcomes, it has become our therapy of choice and perhaps has lowered our threshold for leaving the chest open after cardiac surgery.

\section{Webcast}

You can watch a Webcast of this AATS meeting presentation by going to: https://aats.blob.core.windows.net/ media/18Apr30/28DE\%20Perioperative \%20Care/S73_8. mp4.

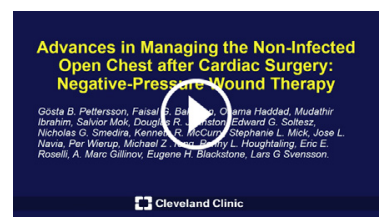

\section{Conflict of Interest Statement}

Dr Gillinov is a consultant for AtriCure, Medtronic, Edwards Lifesciences, Abbott Technologies, and ClearFlow and has a right to equity from ClearFlow. Dr Svensson is a member of the PARTNER Trial Executive Committee (no direct compensation) and receives royalties for the Posthorax vest. All other authors have nothing to disclose with regard to commercial support.

\section{References}

1. Argenta LC, Morykwas MJ. Vacuum-assisted closure: a new method for wound control and treatment: clinical experience. Ann Plast Surg. 1997;38:563-76; discussion: 577.

2. Obdeijn MC, de Lange MY, Lichtendahl DH, de Boer WJ. Vacuum-assisted closure in the treatment of poststernotomy mediastinitis. Ann Thorac Surg. 1999;68:2358-60.

3. Fleck T, Moidl R, Giovanoli P, Aszmann O, Bartunek A, Blacky A, et al. A conclusion from the first 125 patients treated with the vacuum assisted closure system for postoperative sternal wound infection. Interact Cardiovasc Thorac Surg. 2006;5:145-8.

4. Sjogren J, Nilsson J, Gustafsson R, Malmsjo M, Ingemansson R. The impact of vacuum-assisted closure on long-term survival after post-sternotomy mediastinitis. Ann Thorac Surg. 2005;80:1270-5.

5. Fleck T, Kickingera B, Moidlb R, Waldenbergers F, Wolnera E, Grabenwogerb M, et al. Management of open chest and delayed sternal closure with the vacuum assisted closure system: preliminary experience. Interact Cardiovasc Thorac Surg. 2008;7:801-4.

6. Sjogren J, Gustafsson R, Koul B, Ingemansson R. Selective mediastinal tamponade to control coagulopathic bleeding. Ann Thorac Surg. 2003;75:1311-3.

7. The Society of Thoracic Surgeons. Adult cardiac surgery national database data collection. Available at: http://www.sts.org/sts-national-database/databasemanagers/adult-cardiac-surgery-database/data-collection. Accessed December $21,2017$.

8. Blackstone EH, Naftel DC, Turner ME. The decomposition of time-varying hazard into phases, each incorporating a separate stream of concomitant information. J Am Stat Assoc. 1986;81:615-24.

9. Li L, Greene T. A weighting analogue to pair matching in propensity score analysis. Int J Biostat. 2013;9:215-34.

10. Breiman L. Prediction games and arcing algorithms. Neural Comput. 1999;11: 1493-517.

11. Rajeswaran J, Blackstone EH. Multilevel data analysis: what? why? how? J Thorac Cardiovasc Surg. 2018;155:210-1.

12. Sauerbrei W, Schumacher M. A bootstrap resampling procedure for model building: application to the Cox regression model. Stat Med. 1992;11: 2093-109. 
13. Rubin DB. Multiple Imputation for Non-Response in Surveys. New York: Wiley; 1987.

14. Gielchinsky I, Parsonnet V, Krishnan B, Silidker M, Abel RM. Delayed sternal closure following open-heart operation. Ann Thorac Surg. 1981;32:273-7.

15. Christenson JT, Maurice J, Simonet F, Velebit V, Schmuziger M. Open chest and delayed sternal closure after cardiac surgery. Eur J Cardiothorac Surg. 1996;10: 305-11.

16. Furnary AP, Magovern JA, Simpson KA, Magovern GJ. Prolonged open sternotomy and delayed sternal closure after cardiac operations. Ann Thorac Surg. 1992; 54:233-9.

17. Riahi M, Tomatis LA, Schlosser RJ, Bertolozzi E, Johnston DW. Cardiac compression due to closure of the median sternotomy in open heart surgery. Chest. 1975;67:113-4.

18. Ott DA, Cooley DA, Norman JC, Sandiford FM. Delayed sternal closure: a useful technique to prevent tamponade or compression of the heart. Cardiovasc Dis. 1978;5:15-8

19. Boeken U, Assmann A, Mehdiani A, Akhyari P, Lichtenberg A. Open chest management after cardiac operations: outcome and timing of delayed sternal closure. Eur J Cardiothorac Surg. 2011;40:1146-50.

20. Johnson JA, Gundersen AE, Stickney ID, Cogbill TH. Selective approach to sternal closure after exploration for hemorrhage following coronary artery bypass. Ann Thorac Surg. 1990;49:771-4.

21. Josa M, Khuri SF, Braunwald NS, VanCisin MF, Spencer MP, Evans DA, et al Delayed sternal closure. An improved method of dealing with complications after cardiopulmonary bypass. J Thorac Cardiovasc Surg. 1986;91:598-603.

22. Wong JK, Joshi DJ, Melvin AL, Aquina CT, Archibald WJ, Lidder AK, et al. Early and late outcomes with prolonged open chest management after cardiac surgery. J Thorac Cardiovasc Surg. 2017;154:915-24.

23. Fanning WJ, Vasko JS, Kilman JW. Delayed sternal closure after cardiac surgery. Ann Thorac Surg. 1987;44:169-72.

24. Stulak JM, Romans T, Cowger J, Romano MA, Haft JW, Aaronson KD, et al. Delayed sternal closure does not increase late infection risk in patients undergoing left ventricular assist device implantation. J Heart Lung Transplant. 2012;31: 1115-9.

25. Anderson CA, Filsoufi F, Aklog L, Farivar RS, Byrne JG, Adams DH. Liberal use of delayed sternal closure for postcardiotomy hemodynamic instability. Ann Thorac Surg. 2002;73:1484-8.

26. Pettersson GB, Martino D, Blackstone EH, Nowicki ER, Houghtaling PL, Sabik JF III, et al. Advising complex patients who require complex heart operations. J Thorac Cardiovasc Surg. 2013;145:1159-69.e3.

27. Gustafsson R, Sjogren J, Malmsjo M, Wackenfors A, Algotsson L, Ingemansson R. Vacuum-assisted closure of the sternotomy wound: respiratory mechanics and ventilation. Plast Reconstr Surg. 2006;117:1167-76.

28. Sjogren J, Gustafsson R, Wackenfors A, Malmsjo M, Algotsson L, Ingemansson R. Effects of vacuum-assisted closure on central hemodynamics in a sternotomy wound model. Interact Cardiovasc Thorac Surg. 2004;3: 666-71.

29. Malmsjo M, Petzina R, Ugander M, Engblom H, Torbrand C, Mokhtari A, et al. Preventing heart injury during negative pressure wound therapy in cardiac surgery: assessment using real-time magnetic resonance imaging. J Thorac Cardiovasc Surg. 2009;138:712-7.

30. Petzina R, Malmsjo M, Stamm C, Hetzer R. Major complications during negative pressure wound therapy in poststernotomy mediastinitis after cardiac surgery. $J$ Thorac Cardiovasc Surg. 2010;140:1133-6.

31. Arbulu A, Gursel E, Camero LG, Asfaw I, Stephenson LW. Spontaneous right ventricular rupture after sternal dehiscence: a preventable complication? Eur J Cardiothorac Surg. 1996;10:110-5.

32. Partanen J, Verkkala KA, Karhunen PJ, Kauppila R, Nieminen MS. Profuse mediastinal haemorrhage due to mediastinitis after sternotomy. Report of three cases and review of the literature. Scand J Thorac Cardiovasc Surg. 1996;30: 167-73.

33. Matros E, Aranki SF, Bayer LR, McGurk S, Neuwalder J, Orgill DP. Reduction in incidence of deep sternal wound infections: random or real? J Thorac Cardiovasc Surg. 2010;139:680-5.

34. Banbury MK, Brizzio ME, Rajeswaran J, Lytle BW, Blackstone EH. Transfusion increases the risk of postoperative infection after cardiovascular surgery. $J \mathrm{Am}$ Coll Surg. 2006;202:131-8.

35. Horvath KA, Acker MA, Chang H, Bagiella E, Smith PK, Iribarne A, et al. Blood transfusion and infection after cardiac surgery. Ann Thorac Surg. 2013;95: 2194-201.
Key Words: hemodynamics, coagulopathy, survival, propensity score

\section{Discussion \\ Moderator: David A. Fullerton}

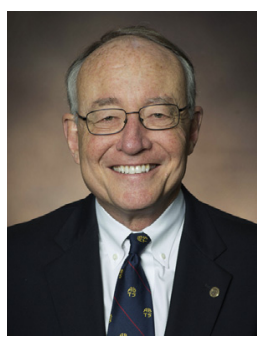

Dr David A. Fullerton (Aurora, Colo). Congratulations not only on an excellent study but very nicely presented. I would just like to introduce my remarks. I would offer that I am gratified to see these data, because anecdotally in our own program, we feel very strongly that this is the way to go. I will share that the introduction of this in our own program was at the stimulus of one of our resident who one night at the end of a long day said, well, why don't we just throw a vac on this, and I basically threw my hands up and said, fine, whatever you want to do. It worked well, so we kept doing it, and now this is, at least in our program as it sounds like in yours, the preferred way to deal with this situation. And I am absolutely convinced that although the mortality rate can still be high depending on what kind of patients you are dealing with, it's much lower than it would otherwise be.

A couple of questions I have for you are I'm just curious as to how you manage this in your own place. First, we have had a couple of instances in which we probably had the suction up too high on the room vac, and by modulating the suction you could witness changes in the hemodynamics. So is there an optimal level of suction that you apply or is there a way to monitor that?

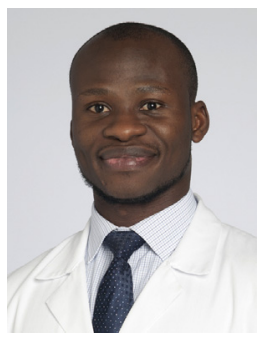

Dr Mudathir Ibrahim (Cleveland, Ohio). Thank you for that very important question. At our institution we try to go on low pressure just to make sure we don't compromise hemodynamics, generally in the range of -50 to -75 .

Dr Fullerton. Another question is, occasionally we have even changed these things either because there has been some bleeding and you need to evacuate that or it's just been on for a couple of days. Do you have any reservations about just changing it at the bedside?

Dr Ibrahim. Thank you again for that question. For bedside changes, one of the most common reasons that we do that, especially in an emergency situation, is for tamponade, and what we have noticed with negativepressure wound therapy management is that frequency of bedside re-exploration is lower, which gives us some time to take patients to the $\mathrm{OR}$ for a 
re-exploration. So we have patients on negative-pressure wound therapy without having to re-explore them, and after they are hemodynamically stable and coagulopathy is corrected, we feel comfortable closing them.

Dr Fullerton. The other question I have is, in our group we have been very gratified by the fact that I don't believe we have had anybody get mediastinitis after this, and yet there are typically people that would otherwise be felt to be at high risk for mediastinitis, and then by having the chest in a delayed sternal closure situation for a couple of days, that was always one of the things that we were concerned about, and yet it hasn't happened. I'm just curious, do you have any insight as to why we don't see more infections with this? And the risk of infection in yours was certainly lower than your traditional pathway.

Dr Ibrahim. That's correct and another very important point. When it comes to infections, our study is not the first to show that patients with open chests, whether managed traditionally or with negative-pressure wound therapy, have an increased but still lower than anticipated risk of infections compared with average cardiac surgery patients.

It's also possible that we have gotten better with patient management and antibiotic coverage. When there is continuous bleeding in the chest, you often see a break in the seal, which is a concern for infection. However, with negativepressure management, evacuation of ongoing bleeding is more effective, resulting in breaks in the seal and reexplorations being less common.

Dr Fullerton. Well, thank you very much, and, once again, very nicely presented.

Dr Ibrahim. Thank you.

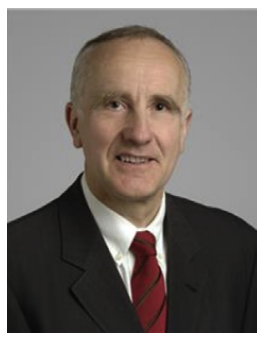

Dr Gösta B. Pettersson (Cleveland, Ohio). Dr Fullerton's experience is very much a copy of ours in that $\mathrm{Dr}$ McCurry had used it in the first case, it worked fine, and then use spread across all staff surgeons and everyone adopted it. I felt embarrassed that we used NPWT for years without investigating what it actually did to outcomes. That was the impetus for this study, and we are very happy that the results confirm we were right in adopting it.

It's also an illustration of how ways of doing things can happen without being scientifically well proven and founded. We have a habit of behaving this way.

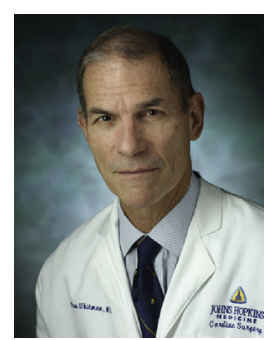

Dr Glenn Whitman (Baltimore, $M d$ ). I think the University of Virginia had a publication where they looked at the incidence of mediastinitis in delayed sternal wound closures. They split the duration of the open chest into 2-day increments and showed that in the first 2 days mediastinitis incidence was very low, and then, for each subsequent 2-day increment, the incidence rose increasingly.

I know that when we see patients who have open chests, we feel pressure to get them closed, sometimes even before we have adequately diuresed them and allowed myocardial recovery, allowing room for the heart within the mediastinum. I wonder if, given the size of your study, you might not look at those patients who do develop wound infections, and determine when that occurred. Perhaps negative pressure dressings might prolong the time to increasing infection incidence, allowing us more time to optimize the patient prior to wound closure, knowing we had 4 or 5 days during which time subsequent infection rates were still extremely low.

Dr Pettersson. I would certainly agree that we should look at that. It's also interesting to note that it's not only about local infection; the overall infection rate was also lower, and that's a little bit more difficult to explain. But I think we got better, more stable patients afterward. We feel less and less pressure to bring patients back too early.

Another observation we have not presented is the secondary open-chest patients who that have their chests opened after being closed primarily; they actually do worse irrespective of which method we use, but still with this trend of the NPWT patients doing better.

Dr Whitman. How do you manage a patient with an open chest and central ECMO?

Dr Ibrahim. In this series we actually had patients who were on ECMO, but they were all on peripheral cannulation and not central. So I would leave that technical question to Dr Pettersson.

Dr Pettersson. We do the same thing, being careful about the sealing around the cannula. We would pick them up through the incision or a separate incision to get optimal position of the cannula. We wouldn't do anything different.

Dr Whitman. Meaning that you do use vac dressings in your open chest centrally cannulated ECMO patients?

Dr Pettersson. Yes, we have done that.

Dr Whitman. Fascinating. 


\section{APPENDIX E1. SECONDARY STERNAL OPENING POSTOPERATIVELY}

Baseline profiles of the 136 patients whose chests were opened secondarily (7 had hemisternotomies) were similar to those of patients who left the operating room with a noninfected open chest, as well as between wound therapy groups. Overall this group experienced worse outcomes (Table E1). There were 70 hospital deaths among the 136 patients $(51 \%), 45 \%$ after negative-pressure wound therapy and $56 \%$ in the traditional wound therapy group. Unadjusted early mortality risk was similar for the entire group whose chests remained open after their index cardiac operation and the secondary open-chest group, but late mortality risk was higher for the secondary open-chest group (Figure E6).

\section{APPENDIX E2. BEDSIDE EMERGENCY RE-EXPLORATION}

A quick and organized response to need for emergency bedside exploration is crucial. Re-exploration is considered when the negative pressure fails to keep the foam sponge sucked in and blood is beginning to break the seal. The surgical fellow and intensivist on call are summoned to the bedside and decide whether re-exploration is needed and if so, whether it should be done at the bedside or in the operating room. We use the following intensive care unit (ICU) preparedness and protocol:

1. Each ICU unit is equipped with a portable operating room light, sternal saw, and power line. Negativepressure wound therapy supplies are stored in each unit.

2. When a patient with an open chest is admitted to the ICU, a pre-prepared open-chest table is positioned at the bedside with the usually required set of instruments, sutures, gowns, drapes, and chlorhexidine prep sticks.

3. When immediate chest exploration is needed, the operating room team (nurses, surgical assistants, perfusionist, and anesthesiologist) is notified.

4. The intensivist, surgical fellow, and ICU nurse are already at the bedside, and 2 additional ICU nurses are mobilized to be available to help as needed. The surgical fellow prepares and directs the chest exploration, and the ICU nurse assigned to the patient acts as the scrub nurse and starts preparing the open-chest table while the ICU intensivist monitors the patient and dictates need for drugs, infusions, and blood products.

5. The operating room team needs 10 to 15 minutes to arrive at the scene and brings a travel cart containing gowns, drapes, sutures, headlight, light source, and bypass/extracorporeal membrane oxygenation cannulae. The team also brings an additional open-chest table containing a more complete open-heart instrument set. The perfusionist sets up an extracorporeal membrane oxygenation circuit that is primed and ready to go in a very short time.

\section{APPENDIX E3. VARIABLES CONSIDERED IN MULTIVARIABLE ANALYSES}

Variables in the semisaturated propensity model used to calculate propensity score are indicated by an asterisk.

\section{Demographics}

Age (years), ${ }^{*}$ sex, ${ }^{*}$ height $(\mathrm{cm})$, weight $(\mathrm{kg})$, body mass index,* body surface area $\left(\mathrm{m}^{2}\right)$, race (black,* white,* other*)

\section{Presentation}

New York Heart Association functional class (I-IV),* emergency operation*

\section{Cardiac Comorbidity}

Preoperative atrial fibrillation,* previous myocardial infarction,* history of endocarditis, * number of previous cardiac operations, complete heart block,* heart failure,* hypertension,* ventricular arrhythmia,* right ventricular function, ${ }^{*}$ tricuspid valve regurgitation grade, ${ }^{*}$ left ventricular ejection fraction $(\%), *$ central venous pressure $(\mathrm{mm} \mathrm{Hg}),{ }^{*}$ pulmonary artery systolic pressure $(\mathrm{mm} \mathrm{Hg}),{ }^{*}$ pulmonary artery diastolic pressure $(\mathrm{mm} \mathrm{Hg}) *$

\section{Noncardiac Comorbidity}

Previous stroke,* pharmacologically treated diabetes (insulin and not insulin-dependent), ${ }^{*}$ peripheral arterial disease, ${ }^{*}$ history of smoking, ${ }^{*}$ chronic obstructive pulmonary disease, ${ }^{*}$ renal failure requiring dialysis, ${ }^{*}$ blood urea nitrogen $(\mathrm{mg} / \mathrm{dL})$, creatinine $(\mathrm{mg} / \mathrm{dL})^{*}$

\section{Preoperative Assist Devices}

Extracorporeal membrane oxygenation,* ventricular assist device,* intra-aortic balloon pumping*

\section{Preinduction Laboratory Values}

Hemoglobin $(\mathrm{mg} / \mathrm{dL}),{ }^{*}$ platelets $($ cells $/ \mu \mathrm{L}), *$ international normalized ratio,* bilirubin $(\mathrm{mg} / \mathrm{dL}),{ }^{*}$ alanine aminotransferase (U/L),* aspartate aminotransferase $(\mathrm{U} / \mathrm{L}),{ }^{*}$ cardiac index $\left(\mathrm{L} / \mathrm{min} / \mathrm{m}^{2}\right)^{*}$

\section{Preinduction Anticoagulation}

Anticoagulation,* (aspirin,* warfarin,* clopidogrel, other)

\section{Procedural}

Coronary artery bypass grafting, ${ }^{*}$ aortic surgery,* aortic valve replacement, aortic valve repair, any aortic valve surgery,* mitral valve replacement, mitral valve repair, 
any mitral valve surgery,* tricuspid valve replacement, tricuspid valve repair, any tricuspid valve surgery, ${ }^{*}$ heart transplantation,* cardiopulmonary bypass time (minutes),* myocardial ischemic time (minutes)*

\section{Intraoperative Blood Products}

Units of red blood cells, * fresh frozen plasma,* platelets*

\section{Indication for Open Chest}

Coagulopathy, hemodynamic compromise, coagulopathy and hemodynamic compromise, ${ }^{*}$ other

\section{Experience}

Date of operation (days from January 1, 2000, to operation) 

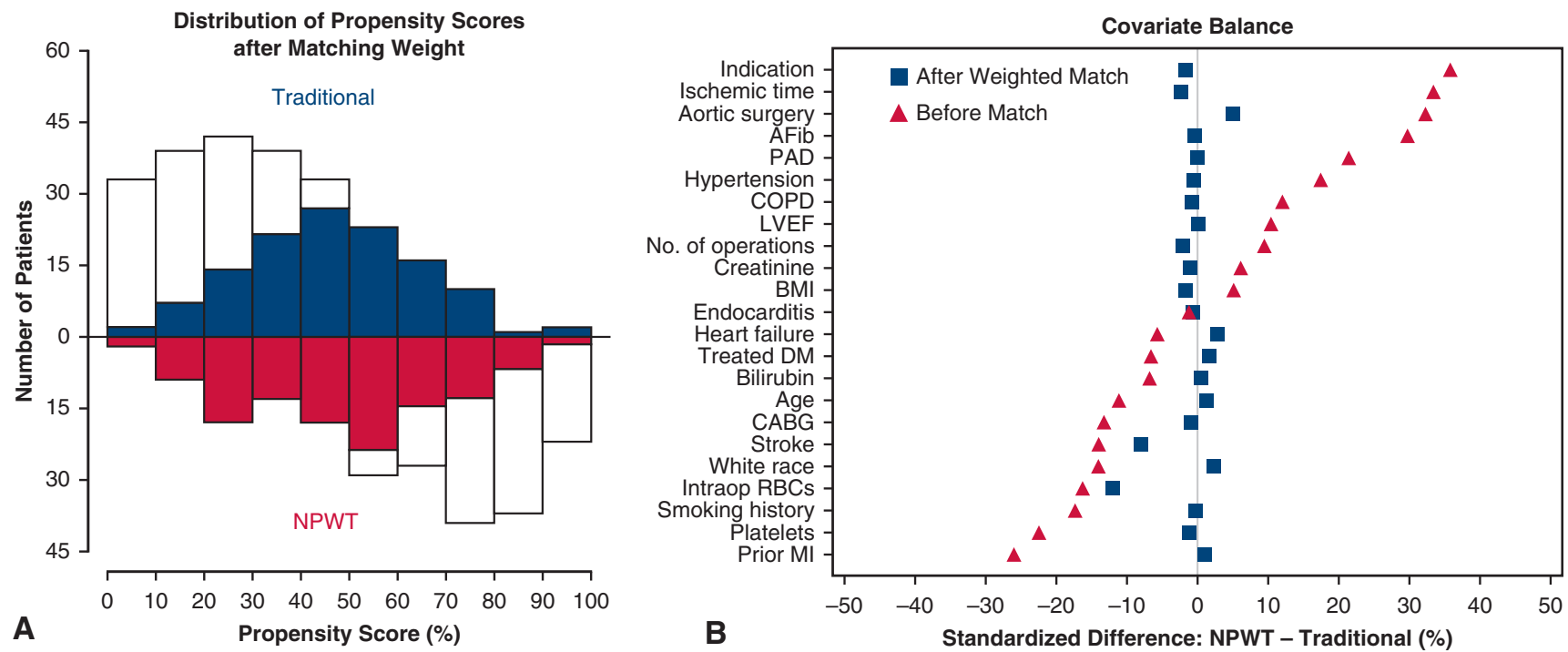

FIGURE E1. Quality of propensity-weighted matching of patients receiving negative-pressure wound therapy (NPWT) and those receiving traditional wound therapy after open-chest cardiac surgery. A, Mirrored histogram of propensity scores between groups. Shaded areas indicate propensityweighted matched patients. B, Standardized difference of selected variables before and after matching, illustrating good matching. Values on horizontal axis represent percent standardized difference between groups. AFib, Atrial fibrillation; $P A D$, peripheral arterial disease; $C O P D$, chronic obstructive pulmonary disease; $L V E F$, left ventricular ejection fraction; $B M I$, body mass index; $D M$, diabetes mellitus; $C A B G$, coronary artery bypass grafting; Intraop, intraoperative; $R B C s$, red blood cells; $M I$, myocardial infarction. 

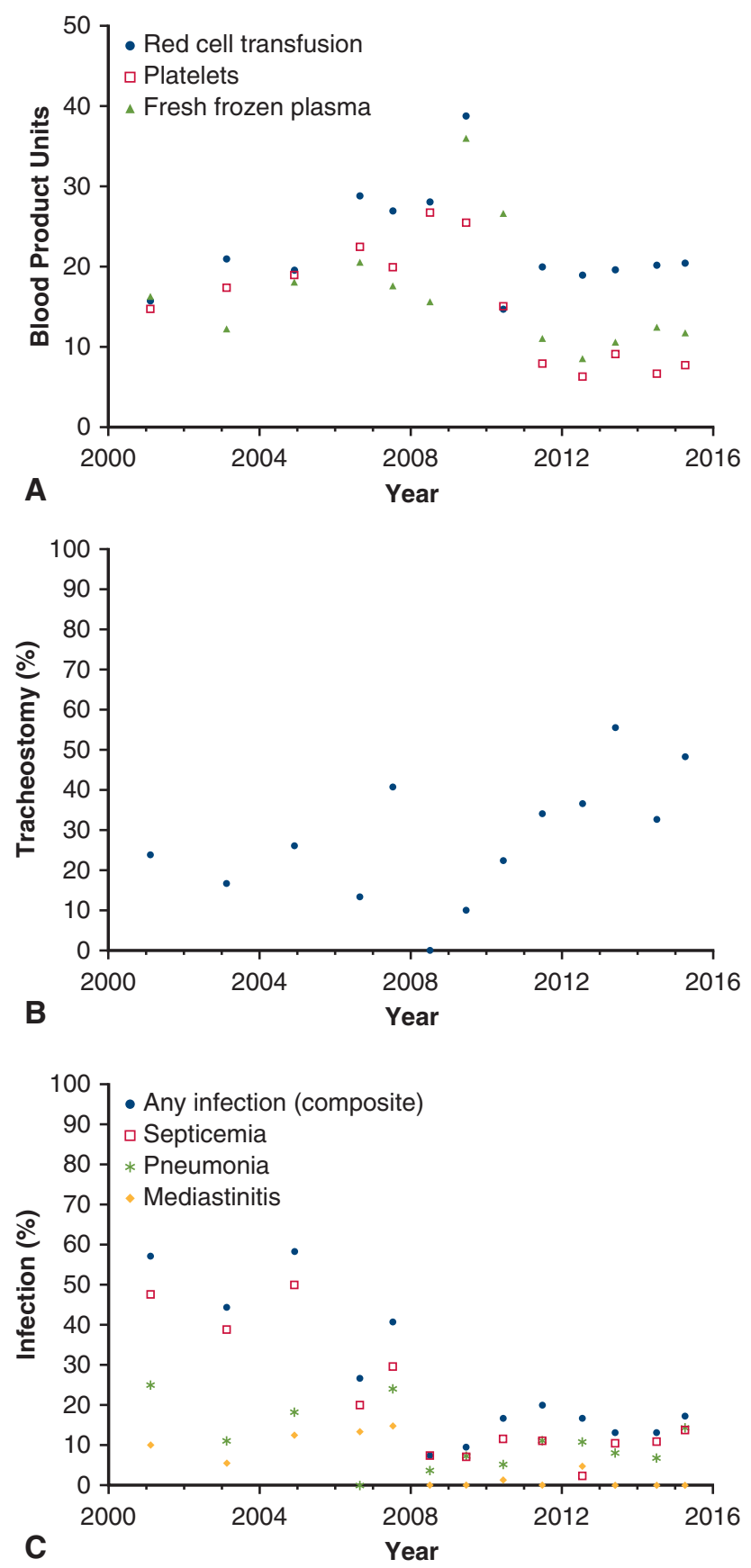

FIGURE E2. Temporal trends. Symbols represent yearly counts or percentages. A, Blood product use. Note that in 2010, a blood conservation quality improvement initiative was introduced. B, Tracheostomy use. With longer durations of open-chest therapy, there was an increased use of tracheostomy to facilitate ventilation and patient comfort. C, Infection. 

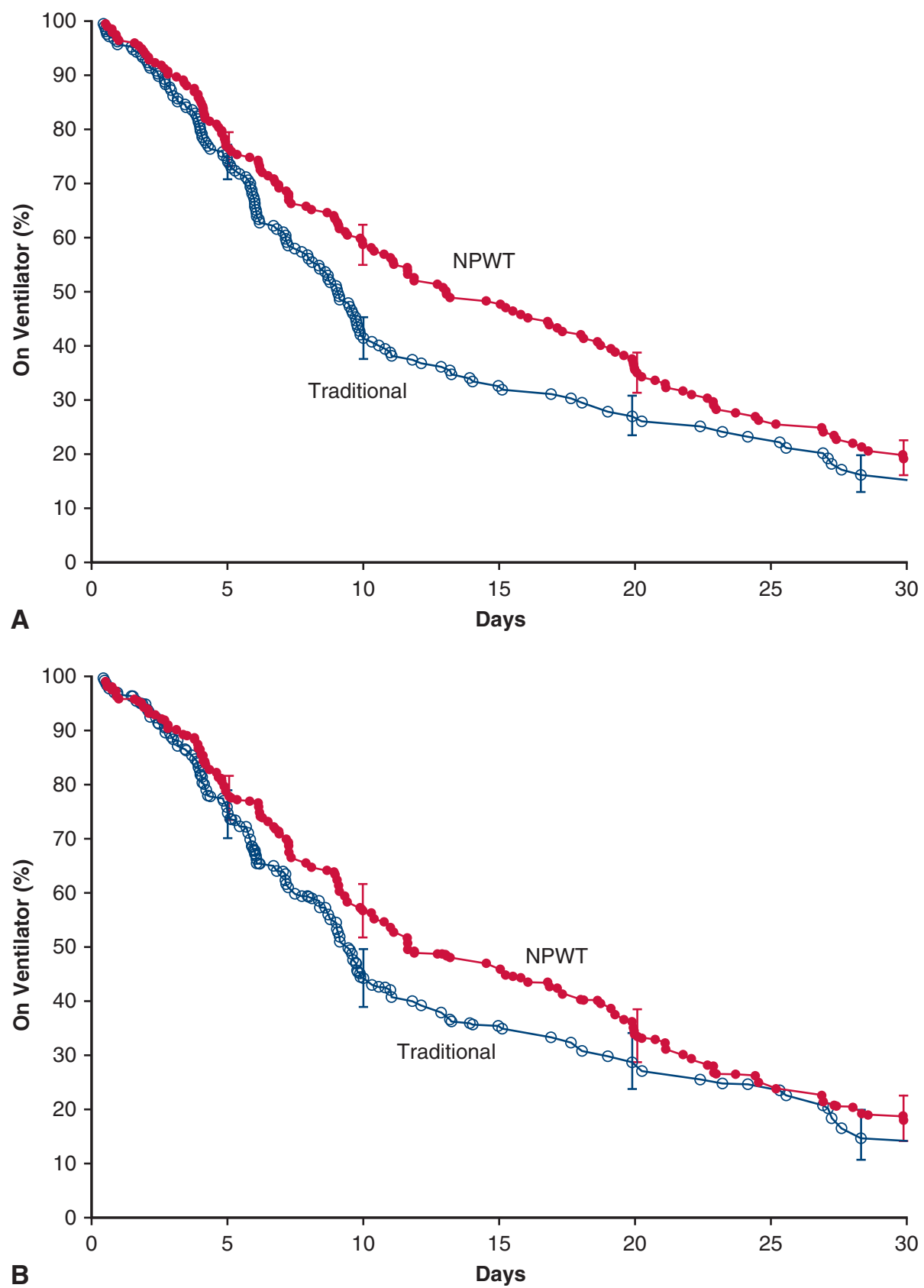

FIGURE E3. Duration of mechanical ventilation. Each symbol represents removal from mechanical ventilation and vertical bars $68 \%$ confidence limits. Closed red circles represent negative-pressure wound therapy (NPWT) patients and open blue circles traditional wound therapy patients. Patients are censored at hospital death. A, All open-chest patients. B, Weighted propensity-matched patients. 

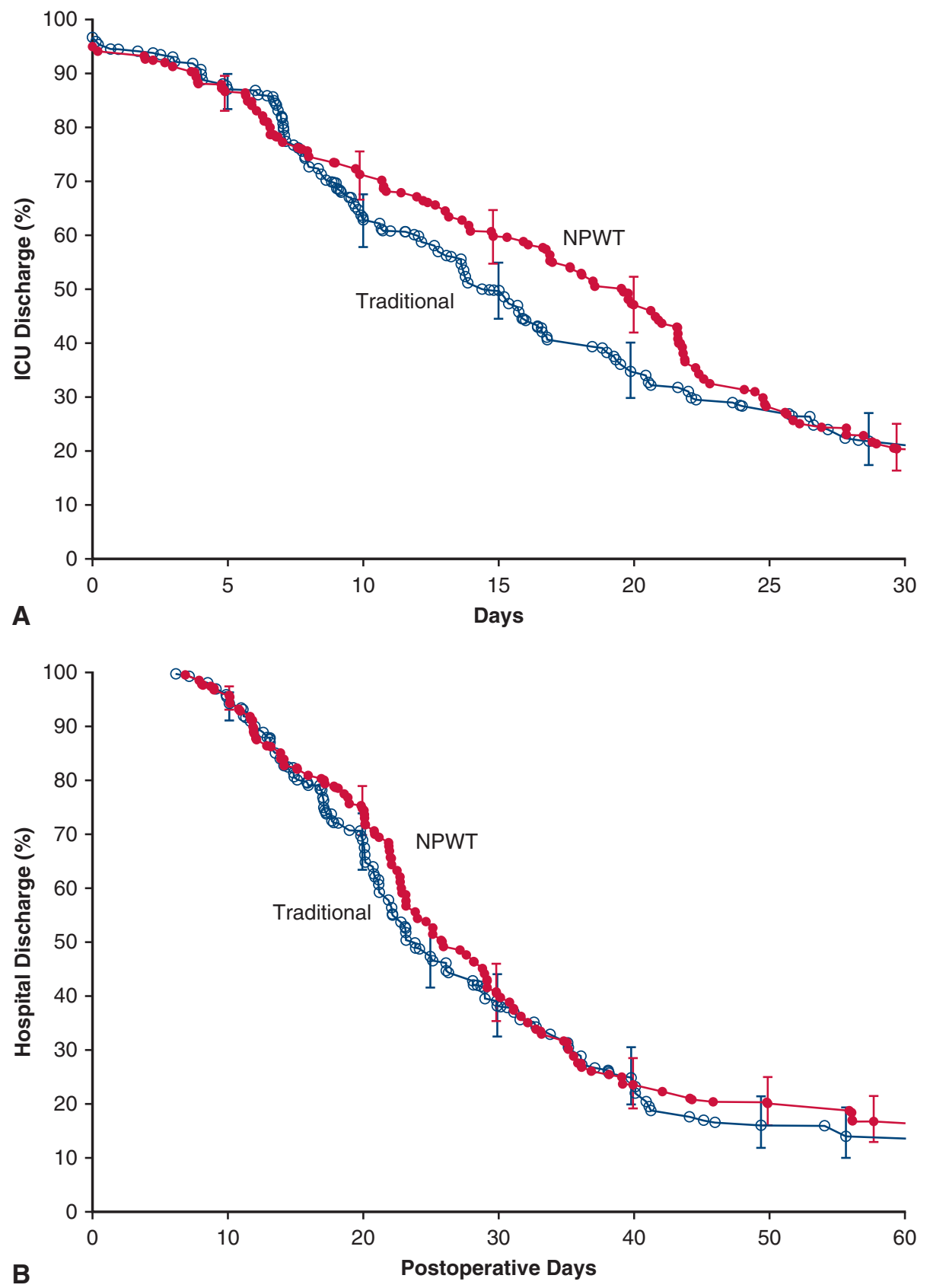

FIGURE E4. Intensive care unit (ICU) and postoperative lengths of stay expressed actuarially to account for hospital deaths, which were censored. Each symbol represents removal from mechanical ventilation and vertical bars $68 \%$ confidence limits. Closed red circles represent negative-pressure wound therapy (NPWT) patients and open blue circles traditional wound therapy patients. Patients are censored at hospital death. A, ICU stay. B, Postoperative stay. 


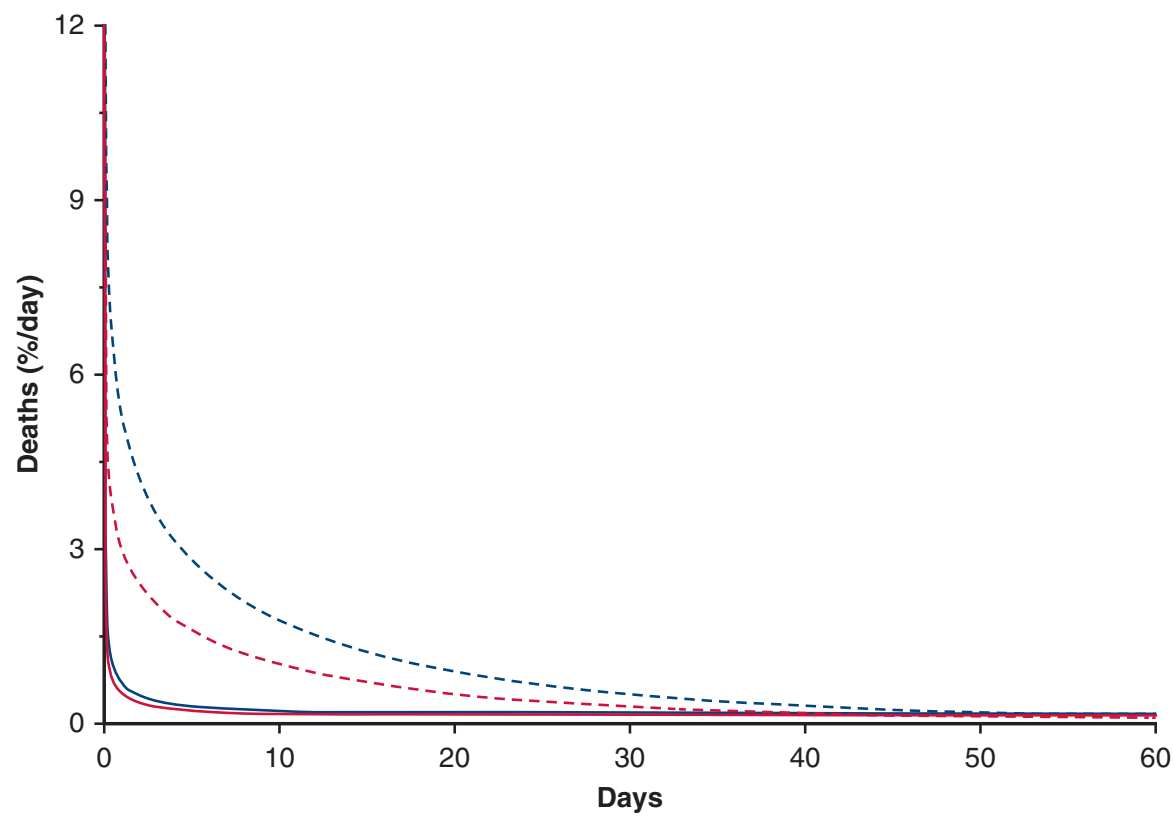

FIGURE E5. Propensity-weighted phases of instantaneous risk of death (hazard phases). Rapidly declining solid lines represent the early phase of hazard and dashed lines the late prolonged phase of hazard. Addition of these phases constitute the overall hazard. Red lines represent negative-pressure wound therapy and blue lines traditional wound therapy.

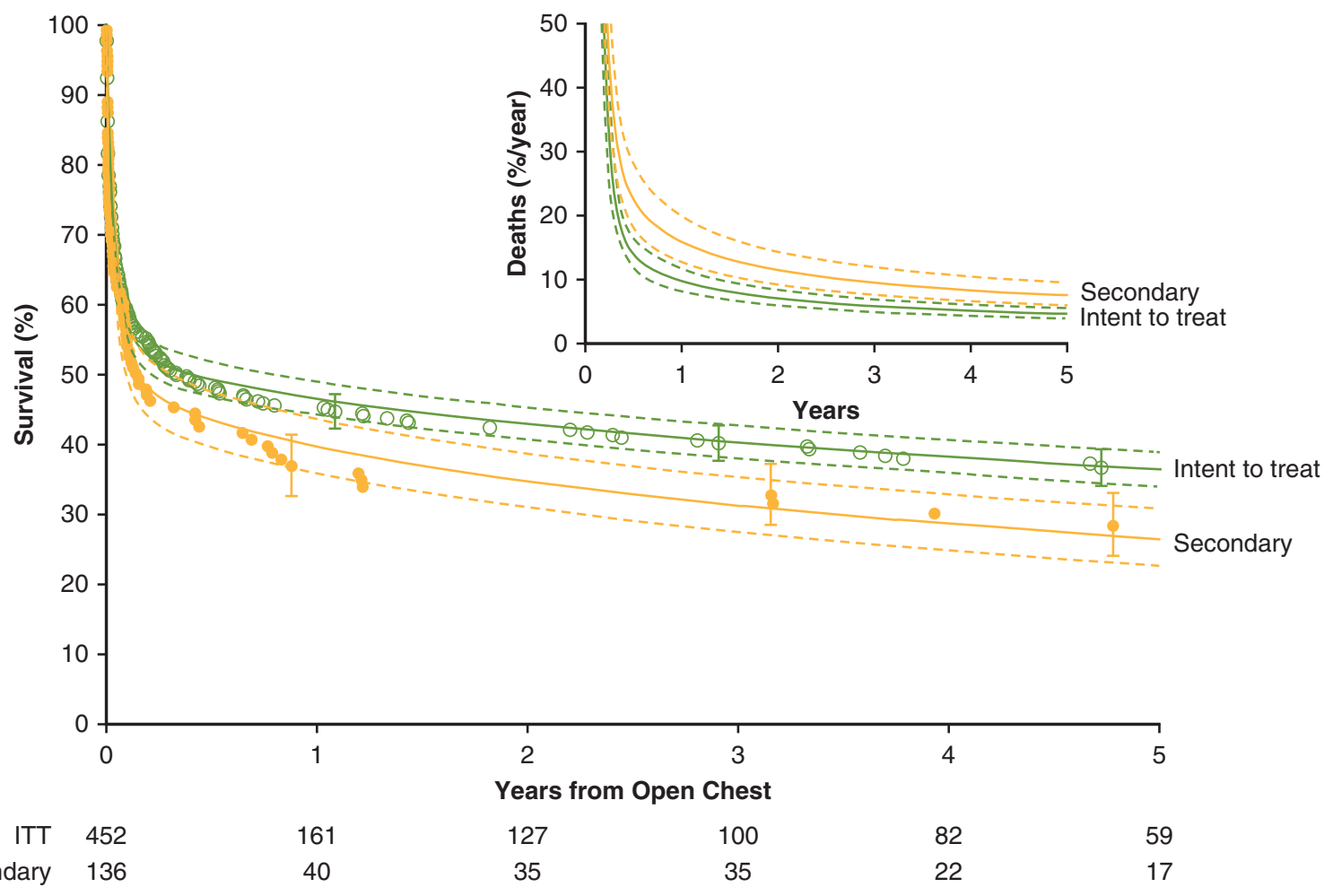

FIGURE E6. Unadjusted survival among patients whose chests were left open in the operating room after the index operation (intent-to-treat [ITT] group, $\mathrm{n}=452$ ) and those whose chests were reopened and left open following closure after the index operation (secondary group, $\mathrm{n}=136$ ). Each symbol represents a death positioned according to the Kaplan-Meier estimator, periodically accompanied by $68 \%$ confidence limits equivalent to \pm 1 standard error. Solid lines represent parametric survival estimates enclosed within a $68 \%$ confidence band. Nonoverlapping $68 \%$ confidence intervals indicate a difference of at least $P$ $<.07$. A graph of hazard functions for mortality is included in the inset. 
TABLE E1. In-hospital morbidity, mortality, and lengths of stay: Primary versus secondary

\begin{tabular}{|c|c|c|c|c|}
\hline \multirow[b]{2}{*}{ Outcome } & \multicolumn{2}{|r|}{ Primary $(n=452)$} & \multicolumn{2}{|r|}{ Secondary $(n=136)$} \\
\hline & $\overline{\mathbf{n}^{*}}$ & No. $(\%)$ or 15 th/50th/85th percentiles & $\overline{\mathbf{n}^{*}}$ & No. $(\%)$ or 15 th/50th/85th percentiles \\
\hline Cardiac, graft, or vascular injury & 452 & $0(0)$ & 136 & $0(0)$ \\
\hline Infectious $\dagger$ & 452 & $100(22)$ & 136 & $46(34)$ \\
\hline Septicemia & 452 & $73(16)$ & 136 & $36(26)$ \\
\hline Mediastinitis & 452 & $15(3.3)$ & 136 & $5(3.7)$ \\
\hline Pneumonia & 436 & $44(10)$ & 135 & $20(15)$ \\
\hline Stroke & 452 & $27(6.0)$ & 136 & $15(11)$ \\
\hline \multicolumn{5}{|l|}{ Blood products used, $\mathrm{U}_{\ddagger}^{\dagger}$} \\
\hline Red blood cells & 445 & $8 / 17 / 33$ & 135 & $5 / 13 / 24$ \\
\hline Platelets & 445 & $3 / 10 / 25$ & 135 & $0 / 7 / 19$ \\
\hline Fresh frozen plasma & 445 & $4 / 10 / 22$ & 135 & $1 / 7 / 20$ \\
\hline Atrial fibrillation & 452 & $150(33)$ & 136 & $48(35)$ \\
\hline Renal failure & 452 & $216(48)$ & 136 & $74(54)$ \\
\hline Dialysis & 452 & $157(35)$ & 136 & $55(40)$ \\
\hline \multicolumn{5}{|l|}{ Respiratory management } \\
\hline Duration of mechanical ventilation, $\mathrm{d} \ddagger$ & 415 & $3.8 / 10 / 32$ & 126 & $3.0 / 12 / 34$ \\
\hline Tracheostomy & 442 & $127(29)$ & 133 & $43(32)$ \\
\hline \multicolumn{5}{|l|}{ Length of stay $\ddagger$} \\
\hline Intensive care unit, $\mathrm{d}$ & 452 & $6.5 / 16 / 39$ & 136 & $8.1 / 27 / 55$ \\
\hline Postoperative, $\mathrm{d}$ & 452 & $14 / 26 / 57$ & 136 & $18 / 36 / 63$ \\
\hline Hospital mortality & 452 & $197(44)$ & 136 & $70(51)$ \\
\hline
\end{tabular}

*Patients with data available. $\dagger$ Combined outcome of sepsis, sternal wound infection, and pneumonia. $\ddagger$ Estimates from actuarial curve.

TABLE E2. Variables associated with negative pressure versus traditional wound therapy (parsimonious model)

\begin{tabular}{|c|c|c|c|c|}
\hline Variable & Estimate $\pm \mathrm{SE}$ & Odds ratio $(95 \% \mathrm{CI})$ & $P$ & Reliability, \%* \\
\hline Peripheral arterial disease & $0.90 \pm 0.25$ & $2.4(1.5-4.0)$ & .0003 & 86 \\
\hline Preoperative atrial fibrillation & $0.82 \pm 0.25$ & $2.3(1.4-3.7)$ & .001 & 82 \\
\hline $\begin{array}{l}\text { Lower preoperative platelet } \\
\text { count, cells } / \mu \mathrm{L} \dagger\end{array}$ & $-0.67 \pm 0.21$ & $0.51(0.33-0.78)$ & .002 & 63 \\
\hline Thoracic aortic procedure & $0.73 \pm 0.23$ & $2.1(1.3-3.2)$ & .001 & 59 \\
\hline Longer ischemic time, hours & $0.26 \pm 0.090$ & $1.3(1.1-1.5)$ & .005 & 61 \\
\hline $\begin{array}{l}\text { Fewer intraoperative } \\
\text { transfused units }\end{array}$ & $-0.058 \pm 0.015$ & $0.94(0.92-0.97)$ & .0001 & 71 \\
\hline Indication for open chest & $1.2 \pm 0.24$ & $3.5(2.2-5.6)$ & $<.0001$ & 96 \\
\hline Intercept & $-0.49 \pm 0.32$ & & & \\
\hline
\end{tabular}

$\overline{S E}$, Standard error, $C I$, confidence interval. *Percent of times factor appeared in 1000 bootstrap models. †Platelets/175, inverse transformation. 
TABLE E3. Exploration of variables associated with infection acquired during open wound therapy

\begin{tabular}{lccc}
\hline \multicolumn{1}{c}{ Risk factor } & Estimate \pm SE & $\begin{array}{c}\text { Odds ratio } \\
(\mathbf{9 5} \% \mathbf{C I})\end{array}$ & $\boldsymbol{P}$ \\
\hline $\begin{array}{l}\text { Indication for open } \\
\text { chest* }\end{array}$ & $-0.122 \pm 0.28$ & $0.88(0.51-1.5)$ & .7 \\
$\begin{array}{l}\text { Date of surgery } \dagger \\
\begin{array}{l}\text { Surgery before } \\
\text { June 2008 }\end{array}\end{array}$ & $-0.134 \pm 0.055$ & $0.88(0.78-0.97)$ & .02 \\
$\begin{array}{l}\text { Negative-pressure } \\
\text { wound therapy }\end{array}$ & $0.49 \pm 0.36$ & $1.9(0.80-4.7)$ & .14 \\
\hline $\begin{array}{l}\text { Propensity score } \\
\text { Intercept }\end{array}$ & $-0.063 \pm 0.61$ & $0.94(0.29-3.1)$ & .9 \\
\hline $\begin{array}{l}S E \text {, Standard error; } C I \text {, confidence interval. *Hemodynamic compromise and coagul- } \\
\text { opathy. } \dagger \text { Years from January } 1,2000 .\end{array}$ & .18 \\
\hline
\end{tabular}

